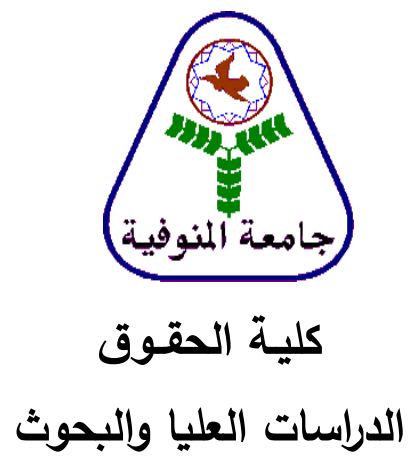

الثمول المالى وأثره فى تحقيق مستهدفات التنمية المستدامة

" دراسة تحليلية لواقع الدول العربية "

$$
\begin{aligned}
& \text { دكتور } \\
& \text { محمه محروس سعدونى } \\
& \text { مدرس الاقتصاد والتشريعات الاقتصادية } \\
& \text { كلية الحقوق / جامعة الزقازيق }
\end{aligned}
$$




\section{ملخص الاراسة}

حُظى الثمول المالى بإهتمام كبير فى الفترة الماضية فى مختلف دول العالم سواء المتقدمه منها أو المتخلفة ، ويرجع ذلك لدوره الكبير فى تحقيق مستهدفات التتمية المستدامة، ولقد ساهمت الثورة التكنولوجية فى مجال البرمجيات فى تعزيز الثمول المالى. ونهدف من هذه الدراسة إلى تطوير دور الثمول المالى فى تحقيق مستهدفات التتمية المستدامة فى الوطن العربى ، لكون أن الثمول المالى أصبح يمثل ركيزة أساسية لمكافحة الفقر ، والبطالة ، ويساهم فى تحقيق النمو الاقتصادى، وذلك من خلال توسيع نطاق الخدمات المالية والمصرفية لمختلف شرائح المجتمع.

وإزاء ما تشهده الدول العربية من تدنى مؤشرات الثمول المالى مع إزدياد حدة الفقر والبطالة ، تظهر اهمية موضوع الثمول المالى وإعطاءه الأولوية باعتباره ركيزة من ركائز تحقيق التنمية المستدامه.

الكلمات الإفتتاحية: الثمول المالى ، القطاع المصرفى ، السياسة النقدية،التنمية المستدامه ، الخدمات المالية والمصرفية.

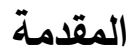

يُعد الثمول المالى فى الوقت الحاضر ركيزه أساسية من ركائز التتمية الاقتصادية لأنه يعمل على مواجهة الفقر والتقليل من حدة البطالة ، خاصة أن دول العالم الثالث التى تظهر التقارير والدراسات أنها تواجه مشاكل إقتصادية ومالية وبالأخص مشاكل تمويل الإستثمار والتتمية لديها معوقات فى تمويل المشروعات الصغيرة ، مما يجعل الحاجة ملحة لتوسيع وتشجيع نطاق الشمول المالى ، وتقديم كافة الخدمات المالية مثل القروض والائتمان والادخار والتأمين والدعم بشكل أكثر فاعلية للمشروعات الصغيرة والمتوسطة نظراً لدورها العام فى التتمية وخلق فرص العمل. 
ومما هو جدير بالذكر أن توسيع نطاق الثمول المالى وتطويره ليس فى حد ذاته هدفاً، بل أداة لتحقيق غاية كبرى ، وذلك لدوره الكبير فى تحقيق مستهدفات التنمية الاقتصادية ، من تحسين مستوى المعيشة وتطوير عنصر العمل ، وتمكين المرأة وتعزيز تكافؤ الفرص، وتمويل المشروعات الصغيرة والمتوسطة ، والحد من الفقر ، وتحقيق العدالة ، وتأمين الرفاهية ، وتحقيق نمو اقتصادى شامل ومستدام.

يساعد الشمول المالى فى الحصول على الائتمان بين جميع شرائح المجتمع الفقراء والأغنياء. وعلى الرغم من حاجة الفقراء إلى الأيتمان أكثر بهدف التعليم

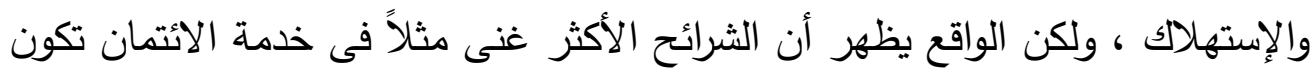

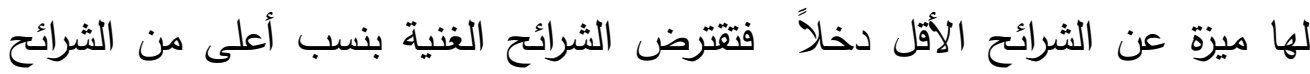
الفقيرة ، وقد يعود ذلك إلى المخاطر المرتفعة المرتبطة بإقتقار المقترضين الفقراء إلى الضمانات الحقيقية كالعقارات فى حال التخلف عن السداد.

يعتبر توفير التمويل اللازم للفقراء واصحاب المشروعات الصغيرة ، أمر بمثابة متطلب من متطلبات التتمية وذلك لتقليص الفقر وتحقيق الترابط الاجتماعى ، ويجب

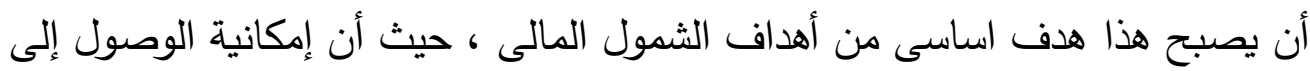
التمويل هو صيغة من صيغ التمكين للمجموعات المعرضة للوقوع فى الفقر • ويشير الثمول المالى إلى تقديم الخدمات المالية بتكلفة يمكن تحملها إلى أجزاء واسعة من غير المحظوظين وذوى الدخل المتدنى. وتثمل هذه الخدمات المالية المتتوعة الأتمان ، والتوفير ، والتامين وتسهيلات الدفع والتمويلات، وأهم أهداف الثمول المالى توسيع نطاق أنشطة النظام المالى المنظم ليشمل ضمن مظلته أناس من ذوى الدخل المتدنى (1).

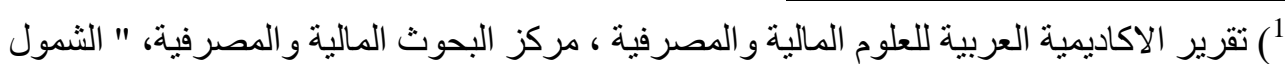

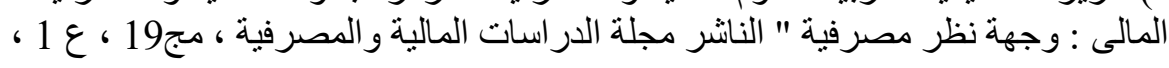


وطبقاً لتقرير البنك الدولى فإن الثمول المالى يعرف على أنه غياب الحواجز السعرية أو غير السعرية فى استخدام الخدمات المالية.

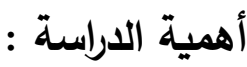

يساهم الثمول المالى فى زيادة مقدرة القطاع المصرفى على جذب الدخرات

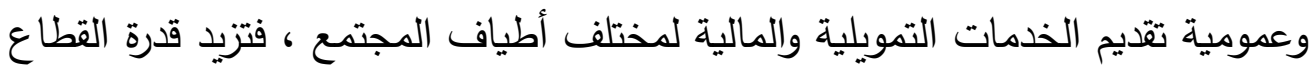

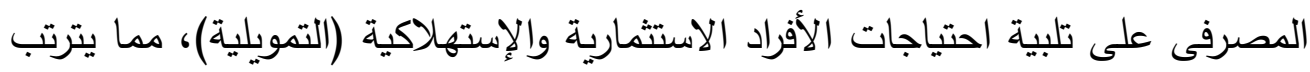

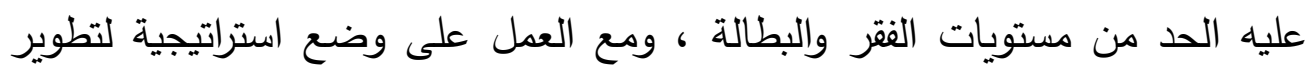

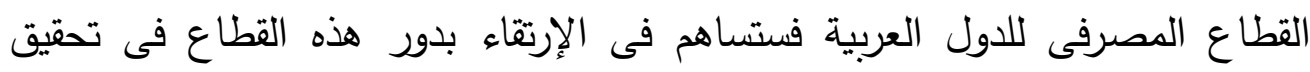

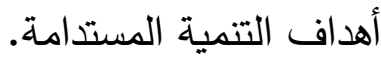

ومع ظهور تحديات كبيرة تواجه القطاع المالى والمصرفى العربى الذى يتطلب

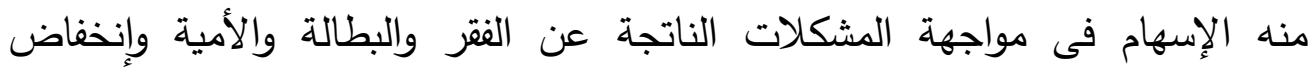

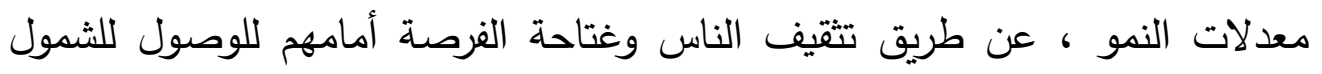

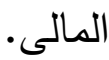

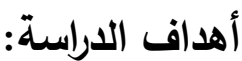

تهدف الدراسة إلى تحديد الدتطلبات الأساسية لتوسيع نطاق الثمول المالى ،

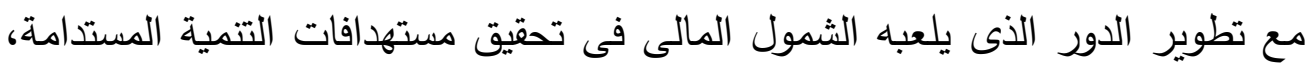

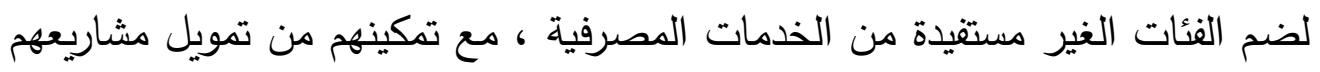

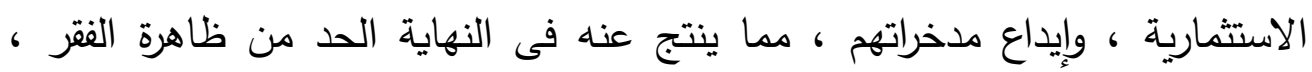
وتقليل البطالة، وتحقيق التنمية الدستدامه. 
ما أثر توسيع نطاق الثمول المالى فى تحقيق مستهوفات التنمية المستدامه فى الدول

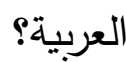

وتتفرع من هذه الإثكالية الأساسية مجموعة إثكاليات تتمثل فى :

$$
\begin{aligned}
& \text { ما ما واقع الثمول المالى فى الدول العربية؟ }
\end{aligned}
$$

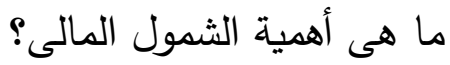

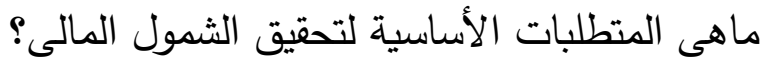

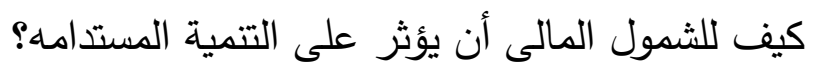

منهج الاراسة:

نظراً لطبيعة الدراسة وتحقيقاً لأهدافها سيستخدم الباحث خليطاً من المناهج

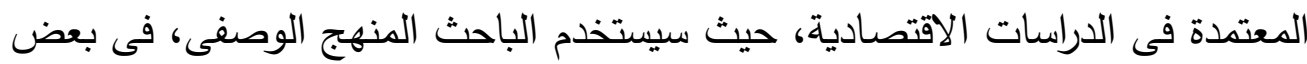

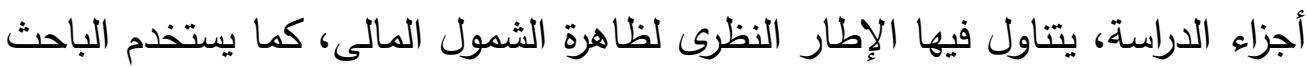

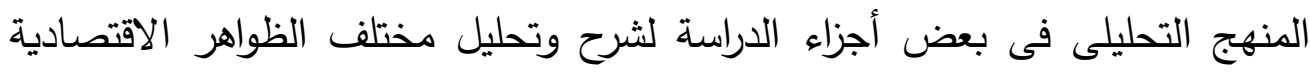
والبيانات التحليلية والإحصاء ات المرتبطة بالظاهرة محل الدراسة.

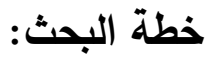

سنعالج موضوع البحث فى خطة قمنا بتقسيمها على النحو التالى: الفصل الأول: ماهية الثمول المالى ونثأته وتطوره.

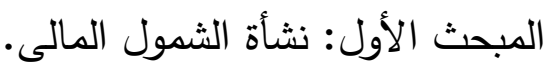
المبحث الثانى : تعريف الثمول المالى.

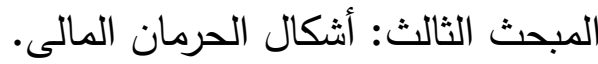
المبحث الرابع : معوقات الثمول المالى. - (لم. 
الفصل الثانى : واقع الثمول المالى فى الدول العربية. المبحث الأول: الثمول المالى وتمويل المشروعات الصغيرة والمتوسطة المبحث الثانى: دور البنية التحتية المالية فى تعزيز الثمول المالى والمصرفى

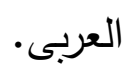

الفصل الثالث : أثر الثمول المالى على التنمية المتدامة. المبحث الأول : مؤشرات التمية المستدامة فى المنطقة العربية. المبحث الثانى : الثمول المالى ركيزة اساسية لتحقيق أهداف التتمية المستدامة. المبحث الثالث : متطلبات تعزيز الثمول المالى فى الدول العربية.

\section{الفصل الأول}

\section{ماهية الثمول المالى ونشأته وتطوره}

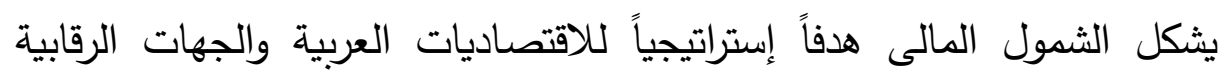

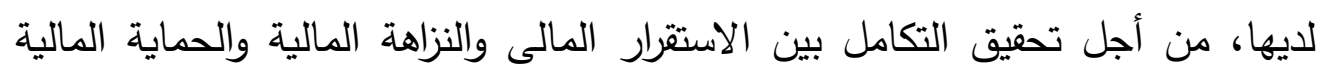

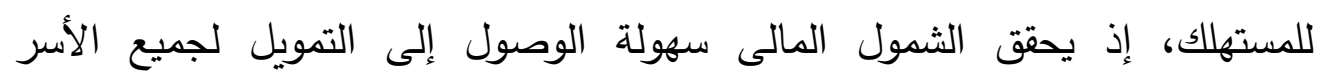

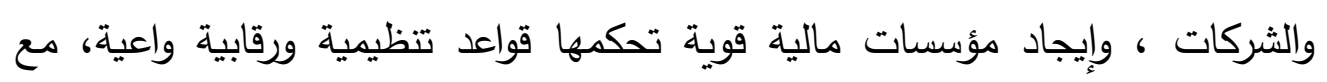
ضمان استدامه مالية لتلك المؤسسات، وتوفير بيئة تنافسية بين مقدمى الخدمات والمنتجات المالية لتقديم وإتاحة البدائل أمام العملاء.

وسنقوم بتقسيم هذا الفصل إلى المباحث الأتية: المبحث الأول: نثأة الثمول المالى. المبحث الثانى : تعريف الثمول المالى. 
المبحث الثالث: أشكال الحرمان المالى.

المبحث الرابع : معوقات الثمول المالى. الثمان.

\section{المبحث الأول}

\section{نشأة الشمول المالى الماولى}

ظهر مصطلح الثمول المالى لأول مرة فى عام 1993 فى دراسة "لثون

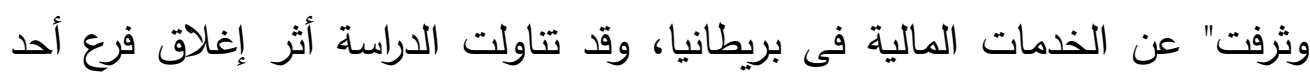

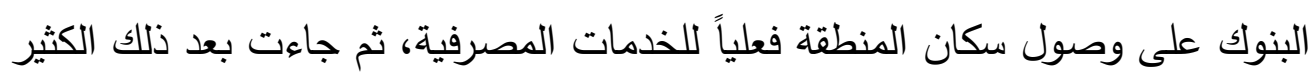

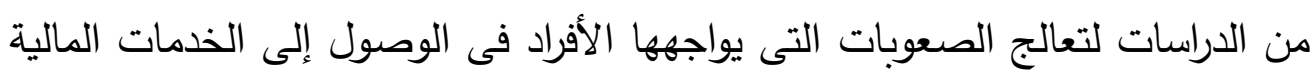
والمصرفية وغير الدصرفية(2).

وقد استخدم مصطلح الثمول المالى بثكل واسع وبدقة فنية وإحترافية منذ عام

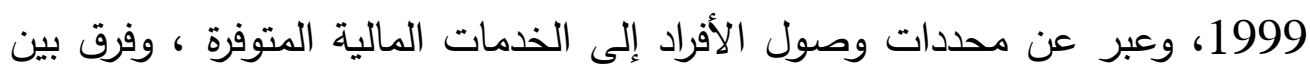

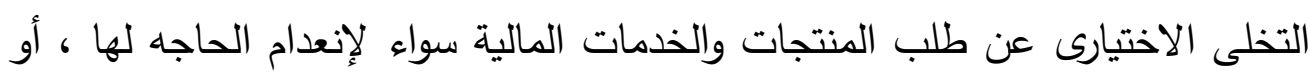

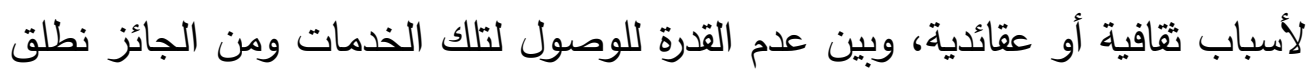

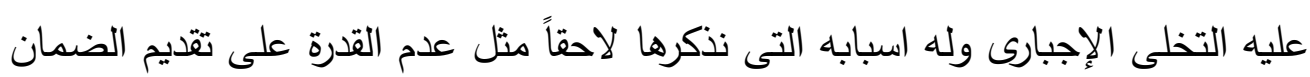
الكافى (3)

وفى اعقاب الأزمة المالية العالمية عام 2008 والتى سببت ضرر لمعظم اقتصاديات العالم ، ازداد الاهتمام الدولى بالثمول المالى ، وتمثل ذلك بالكالت التزام الحكومات المختلفة بتحقيق الثمول المالى من خلال تتفيذ سياسات تهدف إلى تعزيز

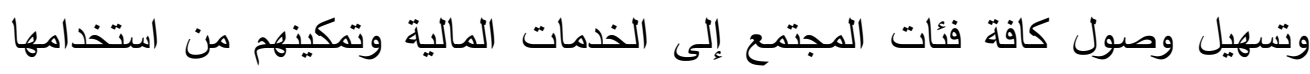

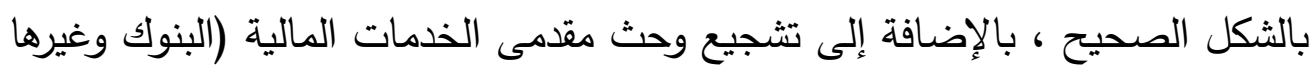
من المؤسسات المالية ) على توفير خدمات متتوعة ومبتكرة بتكلفة منخفضة. وال) د/ صبرى نوفل ، الثمول المالى فى مصر وبعض الدول العربية، مقال ، مجلة الاقتصاد

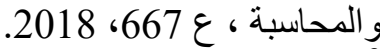

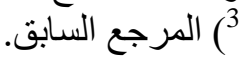


واعتبر البنك الدولى الثمول المالى المتمثل فى تعميم الخدمات المالية وتسهيل وصول جميع فئات المجتمع إليها ركيزة أساسية من اجل محاربة الفقر المدقع وتعزيز

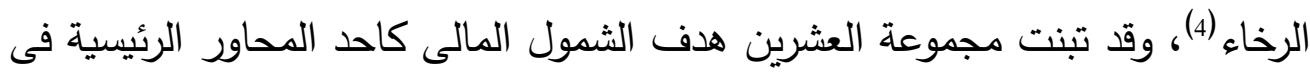
خطة التتمية الاقتصادية والمالية.

واطلقت مجموعة البنك الدولى فى عام 2013 البرنامج العالمى للاستفادة من

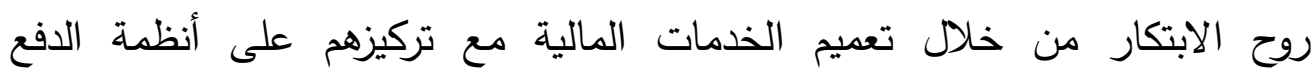
ومدفوعات التجزئة المبتكرة، وتوالت البرامج والخطط فى هذا الثأن وأطلقت العديد من المؤسسات العالمية ، مثل مؤسسة التمويل الدولية (IFC) ، والمجموعة الاستثارية

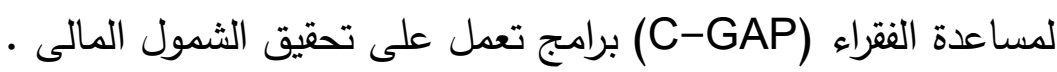

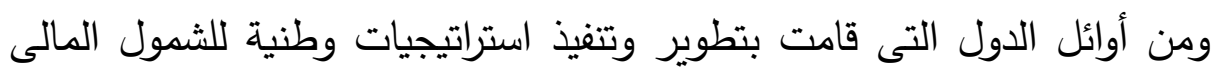

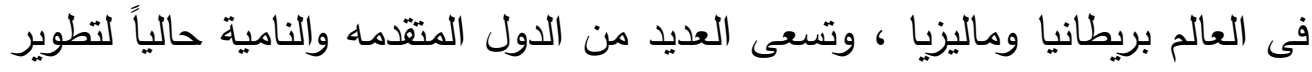

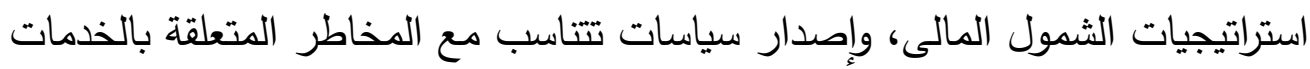

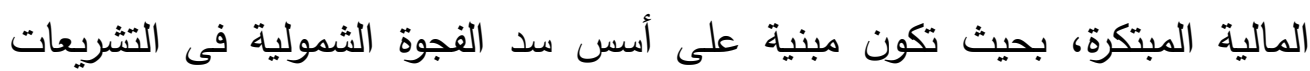
الحالية ، واتباع نهج شامل مبنى على تثريعات عادلة وشفافة لحماية حقوق مستهلكى

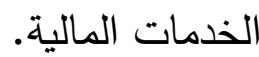

\section{المبحث الثانى \\ تعريف الشمول المالى}

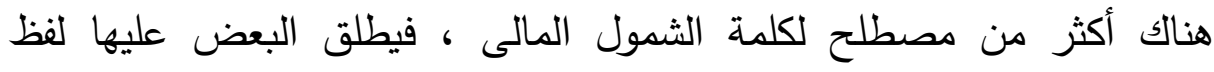

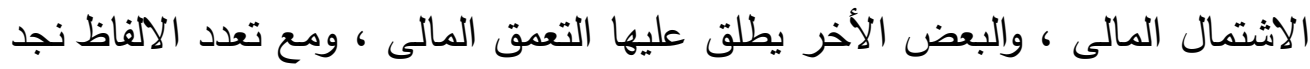
أن الدلالة واحدة التى تعنى تطور المؤسسات المالية والمصرفية ، وزيادة فاعلية

${ }^{4}$ ) Douglas Randall and Jennifer Chien, "8 key approaches to accelerate financial inclusion", World Bank, 2017, See Web Site:

http://blogs.worldbank.org 
السياسة النقدية وتتويع ادواتها بهذف زيادة جهود المتعاملين لجذب ذوى الدخول

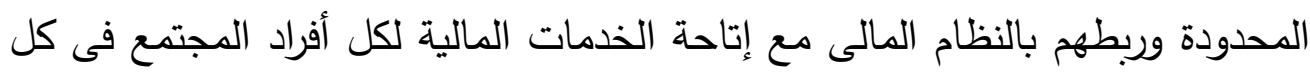
المناطق النائية منها والمتحضرة ، وعن طريق كل المؤسسات المالية والمصرفية مباشرة أو بطريقة غير مباشرة مثل التعامل مع وكلاء المحفظة الاكترونية.

تمثل درجة التعقق النقدى عرض النقود بالمعنى الواسع منسوبة إلى الناتج المحلى الإجمالى بالأسعار الجارية ومعكوس هذة النسبة يعطى سرعة دوران النقود. وكلما زادت درجة التعمق النقدى انخفضت سرعة دوران النقود ولعل انخفاض الثمول النقدى وزيادة سرعة دوران النقود يعكس تضاؤل الوساطة المالية من خلال عدم مقدرة النظام الدصرفى على استقطاب مزيد من الددخرات وتستخدم درجة التعمق النقدى كمؤشر من مؤشرات الثمول المالى(5).

ويستخدم مصطلح الثمول المالى والحرمان المالى بالتبادل لتعريف مدى قدرة

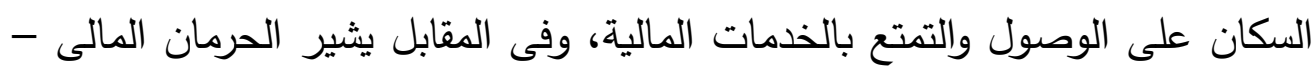
والذى سنوضح أشكاله فى المبحث الثالث من هذا الفصل - إلى العملية التى بموجيها يواجه أفراد المجتمع المصاعب والعوائق فيما يتعلق بالوصول إلى مصادر منتجات

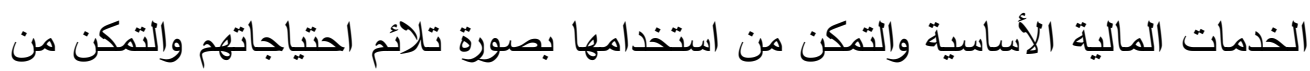
ممارسة حياة اقتصادية طبيعية فى المجتمع الذى يعيشون فيه (6).

وقد عرفت مجموعة العشرين (G20) والتحالف العالمى للشمول المالى (AFI) الثمول المالى بأنه مجموعة الإجراءات التى تتخذها الهيئات الرقابية لتعزيز وصول التهال

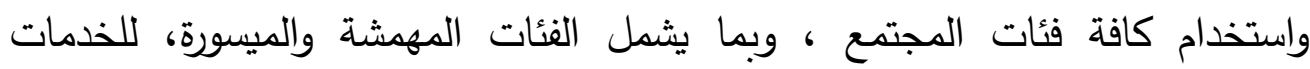

5) اشرف عمر عبدالقادر ، وأخرين : دور التقنية المحترفية فى نشر الثمول المالى : دراسة حالة

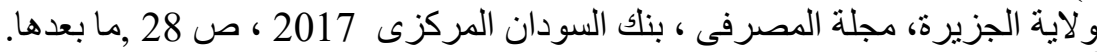

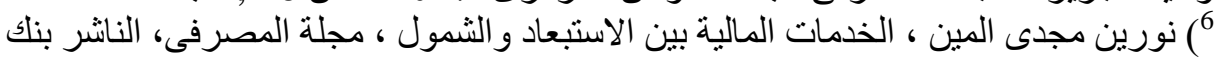
السودان المركزى، العدد 77، سنة 2015، ص صل 5 وما بعدها. 
والمنتجات المالية التى تتناسب مع احتياجاتهم وان تقدم لهم بثكل عادل وشفاف

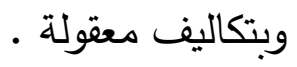

وعرفت منظمة التعاون والتتمية الاقتصادية ( OECO) الثمول المالى بأنه : العملية التى يتم من خلالها تعزيز الوصول إلى مجموعة واسعة من الخدمات والمنتجات المالية الرسمية والخاضعة للرقابة فى الوقت والسعر المعقولين وبالثكل الكافئ، وتوسيع نطاق استخدام هذه الخدمات والمنتجات من قبل شرائح المجتمع التئح المختلفة، ومن خلال تطبيق مناهج مبتكرة تثمل التوعية والتثقيف المالى ، وذلكاقل بهدف تعزيز الرفاه المالى والاندماج الاجتماعى والاقتصادى.

أن الثمول يهذف إلى تعميم المنتجات والذدمات المالية والمصرفية بتكاليف معقولة على العدد الأكبر من المجتمعات والمؤسسات والأفراد، خصوصاً شرائح الدخل

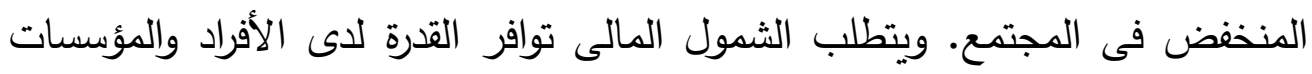

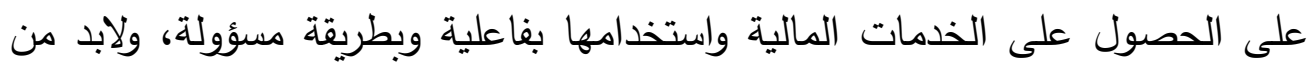
نثر الوعى المانل والمصرفى لاى مافة الطياف ، فالمستهلك الواعى يُعتبر أكثراً إدراكاً للمخاطر والأرباح المرتبطة بالمنتجات المالية.

واتساع نطاق الثمول المالى وكبر مظلته لن يؤدى إلى تحسين أحوال الأفراد

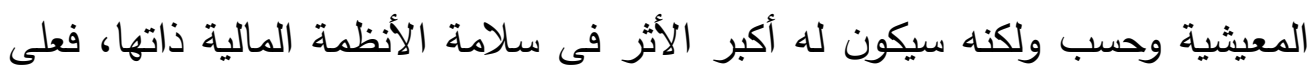

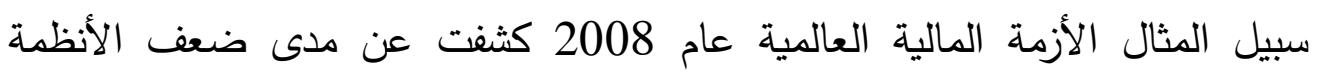

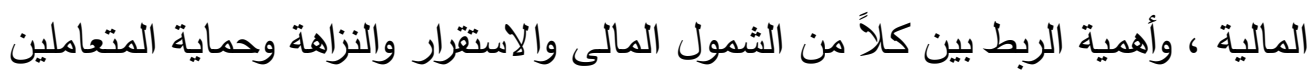
مع المؤسسات المالية ومنتجاتها.

ولتحقيق الشمول المالى يتطلب الأمر تقديم مجموعة متكاملة من الخدمات

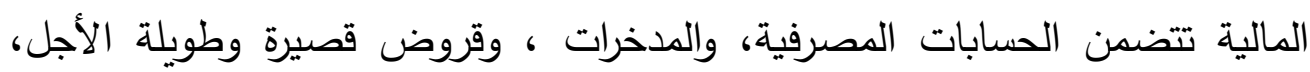

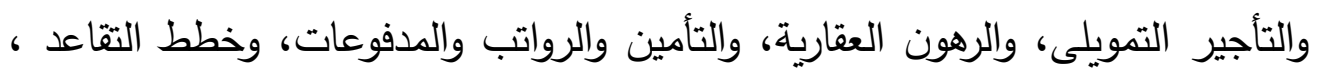


والتحويلات المالية المحلية والدولية، بالإضافة إلى حماية المستهلك وتعزيز القدرة

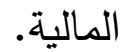

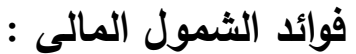

مظلة الثمول المالى لها فوائد عديدة من أهمها(7):

هماية الدذخرات: حيث ان أغلب مدخرات الطبقة البسيطة مبالغ ضئيلة عندما

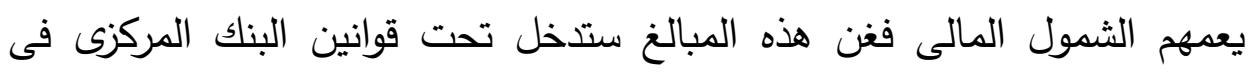

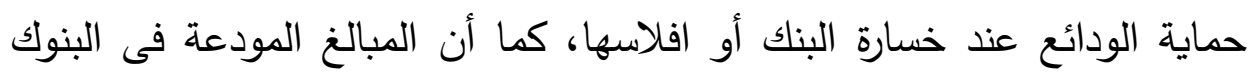

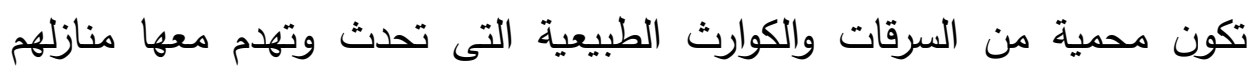
البسيطة.

تحقيق التتمية الإجتماعية من خلال تمكين الفئات المهشة من الرجال والنساء للقيام بدورهم المنوط بهم فى تتمية المجتمع وتحسين أوضاعهم الاقتصادية والاجتماعية، وقد عرفت قمة كوبنهاجن الاجتماعية لعام 1995 تعريف التتمية الاجتماعية بثلاث معايير أساسية وهى : الوئام بين الناس، القضاء على الأئى الفتر ، التوظيف (8). • تحيق الاستقرار المالى : حيث من الصعب استقرار النظام المالى من دون الثمول

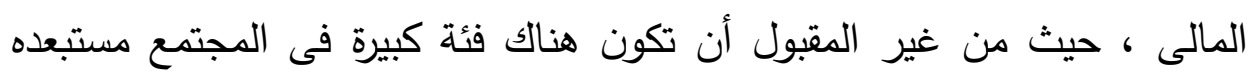

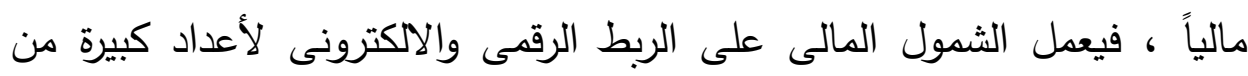

(7)

- World Bank, 2015, The Little Data Book on Financial Inclusion. Institute of International Finance, 2015, Financial Inclusion: A Financial Industry Perspective

${ }^{8}$ ) http://ijsrm.in/special\%20issue\%202/3\%20ijsrm.Pdf 
الطبقة البسيطة وذوى الدخل المحدود بمقدمى الخدمات المالية والخدمات الحكومية والثركات (9).

الثمول المالى يمكن الطبقات البسيطة ومحدودة الدخل من المساهمة فى الاقتصاد بشكل أوسع الثمول المالى يساعد على تتبع التدفقات المالية مما يؤدى إلى معاملات أكثر أمنا وأسرع وكذلك الحد من الفساد والسرقة. الثمول المالى يساعد على تسديد الفواتير ، ودفع الجور بطريقه أكثر سهوله

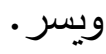
ويكون للشمول المالى آثاره الإيجابية على القطاع المصرفى فى تنويع الصول

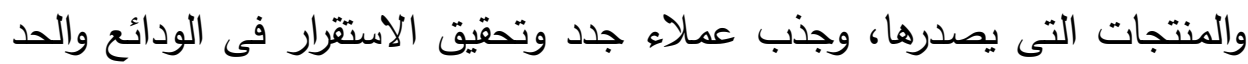
من مخاطر السيولة، فضلاً عن توفير قاعدة بيانات ضخمة للمؤسمات ولمدات المالية بشكل يفيد فى التحليل عند طرحها منتجات جديدة تشبع احتياجات تلك الشرائح وبناء نماذج التقييم الائتمانى لتيسير الحصول على التمويل. المبحث الثالث

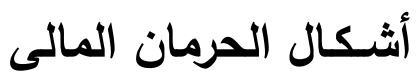

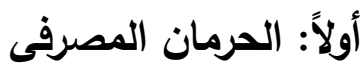

ويقصد بالحرمان المصرفى عدم التمكن من الوصول للخدمات المصرفية وإستخدامها ، وتتمثل أهم مظهر من مظاهره فى الحصول على حساب مصرفى فعندما نجد شخص ليس لديه حساب مصرفى ، فهذا الشخص سيكون تحت مظلة الحرمان المصرفى مما ينتج عن ذلك الكثير من السلبيات مثل :

9) H R Khan: Financial inclusion and financial stability: are they two sides of the same coin Address by Shri H R Khan, Deputy Governor of the Reserve Bank of India, at BANCO , 2011, organized by the Indian Bankers Association and Indian Overseas Bank, Chennai,4 November 2011. 
تعرضه لـخاطر السرقه ، فالحساب المصرفى يضمن للأفراد الحفاظ على أموالهم وعدم تعرضهم للسرقات.

التعامل البيروقراطى والروتينى العقيم فى الحصول على ايراداتهم مثل (الراتب ، المعاش) ، أما الثمول المالى يتيح لهم الاستفاده من التحويلات المالية. عدم التمكن من استخدام الأدوات المصرفية فى تسوية مدفوعاتهم مثل استخدام الشيكات.

فقد القدرة فى الحصول على القروض أو التمويل. عدم الاستفاده من خدمة التحويلات الإككترونية والتى تعتبر أقل تكلفة وأكثر

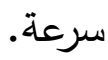

والحرمان المصرفى ليس على وتيرة واحدة ايى ليس على إطلاقه (الحرمان

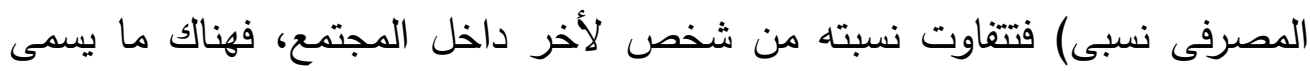
بالحرمان المصرفى الكلى : والمقصود به أن مجموعة أفراد داخل المجتمع محرومين لتصن تماماً من اى نوع من انواع الخدمات المصرفية، والحرمان المصرفى الجزئى، والمقصود

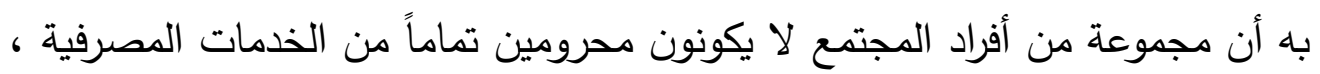
وفى نفس الوقت لا يستفيدون من جميع الخدمات المصرفية ومثال ذلك قد يكون لدى الشخص حساب مصرفى جارى ولكنه لا يستفيد من تسهيلات الدفع الإكترونى مثلاً، أو بطاقات الائتمان أو خدمات الثيكات.

ثانياً: الحرمان الادخارى.

ومفاد الحرمان الادخارى هو عدم وضع الأفراد لمدخراتهم فى البنوك ، ويعتبر الحرمان من الادخار هو نتاج للحرمان الاجتماعى وليس أحد أسبابه، وترتبط فكرة

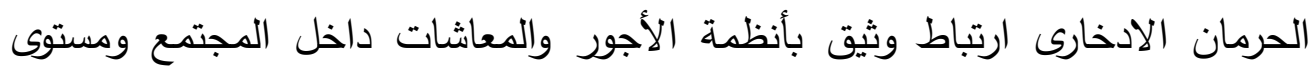
الرفاهية الاقتصادية. وإن كان يتسبب الحرمان المصرفى فى حدوث معاناة للفرد فيما 
يتعلق بحياته اليومية، بينما يتعلق الحرمان الادخارى بمسألة أشد خطورة ولها تداعيات أكبر على حياة الفرد المتمثله فى الحرمان الاجتماعى (10).

ثالثاً: الحرمان الائتمانى:

مما هو لا شك فيه ان الائتمان (القروض) تعتبر اداة مالية جوهرية تمكن الأفراد

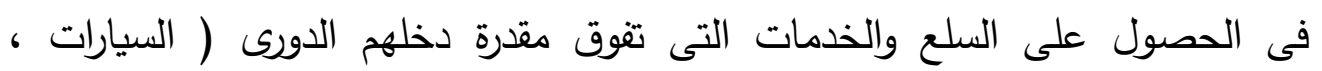

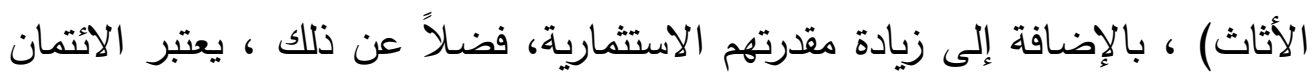

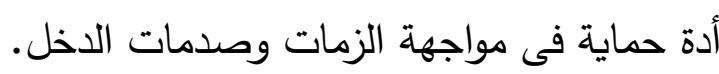

والحرمان الأيتمانى مثله مثل الحرمان المصرفى تتفاوت مستوياته ما بين أفراد المجتمع ويختلف من شخص للآخر، فنجد أن هنالك ما يسمى بالحرمان الائمانى الكلى والمتمثل فى ان هناك مجموعة من افراد المجتمع لا تتاح لهم فرصة الوصول إلى هذه الخدمه مطلقاً. وهناك نوع أخر أقل حدة من النوع الأول وهو الحرمان الأتتمان الغير متتاسق أو غير ملائم: ويقصد به أن أفراد المجتمع الذين يتلقون خدمة الائتمان

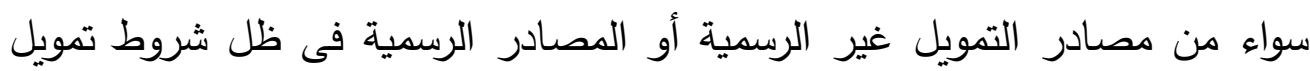
غير مناسبة. - فيما يخص بتكلفة التمويل - مقارنة مع سعر الفائدة السائد فى السوق.

رابعاً: الحرمان التامينى:

${ }^{10}$ ) Adeyemi Adewale Abideen, Pramanik Ataul Huq, Meera Ahmaed

Kameel Mydin, The measurement Model of the Determinants of financial Exclusion among Musilm Micr-enterpreneurs in Ilorin, Nigeria, Journal of Islamic finance, Vol.1 No. 1 (2012), IIUM instititue of Islamic Banking and Finance, ISSN 2289-2117 (O)/2289-2109(P) 
يقصد بالحرمان التأمينى أن هناك مجموعة من أفراد المجتمع تقع خارج مظلة

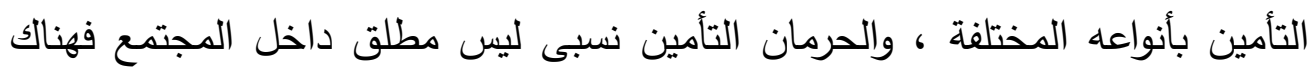

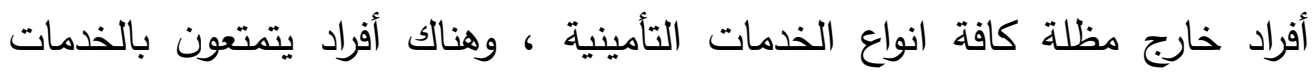
التأمينية بصورة جزئية، وهناك من يتمتع وتتاح له هذه الخدمات بأجمالها.

وبنظرة واقعية داخل مختلف المجتمعات نجد أن خدمات التأمين منها ما يأخذ

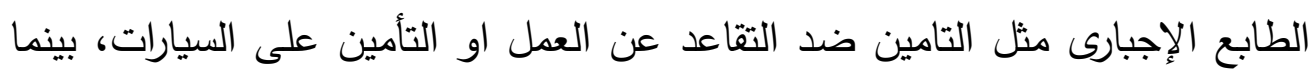

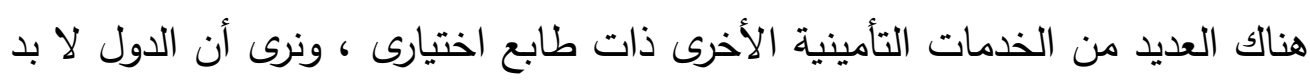

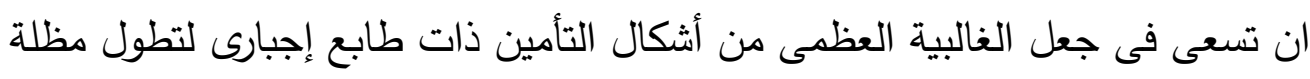

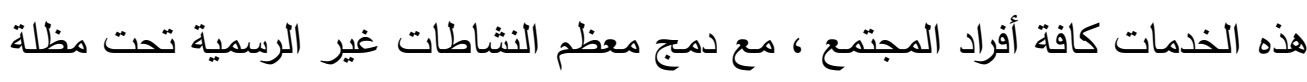

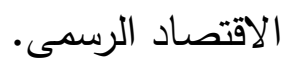

\section{المبحث الرابع}

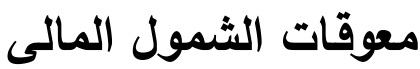

هنالك العديد من المعوقات التى تقف حاجز امام انتثار وتقديم كافة الخدمات

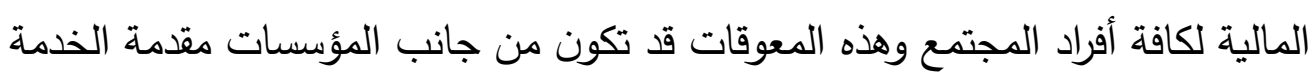

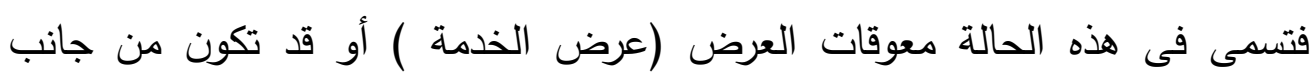
المستهلكين طالبى الخدمات فنطلق عليها معوقات الطلب (طلب الخدمة ).

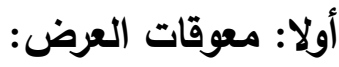

دائما ما تسعى المؤسسات المالية إلى تحقيق اكبر ربح مككن من خلال تقديم

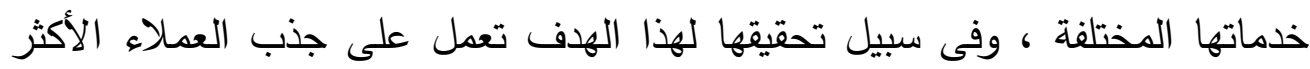

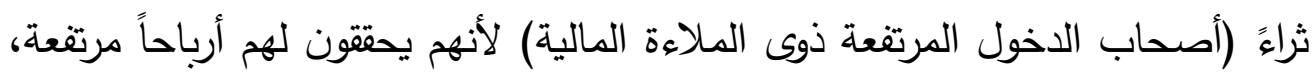


وعلى النقيض تهرب تلك المؤسسات من التعامل مع اصحاب الدخول المتننية لأنهم يحقون لهم أرباح متدنية.

وفيما يخص التوزيع الجغرافى للمؤسسات المالية الرسمية ، نجد ان هناك ضعف

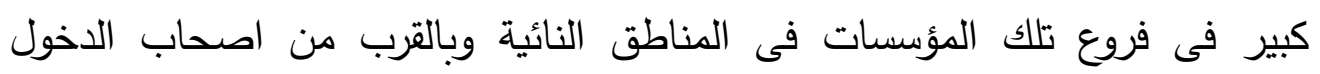
البسيطه، وبالتالى هذه الطوائف لا تتوافر لهم التسهيلات والخدمات المالية فى النطاق

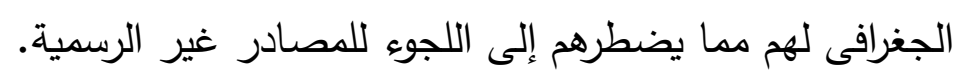

وان حدث وتمكن أصحاب الدخول البسيطة الوصول للمؤسسات المالية الرسمية

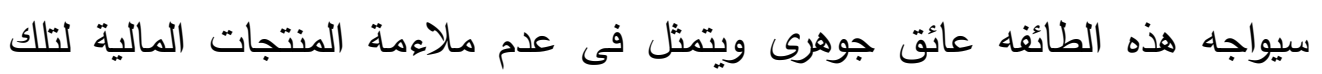

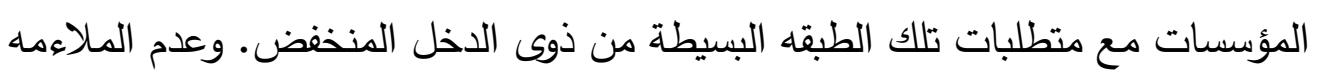
قد يتمثل فى (تكلفة التمويل ، أو شروطه أو أنظمة إجراءات السداد ، الخ ل....).

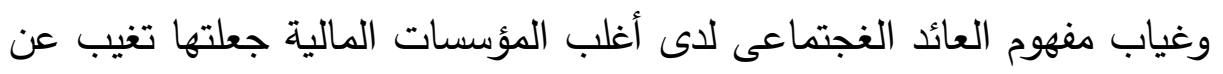

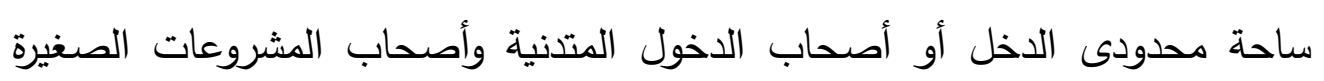

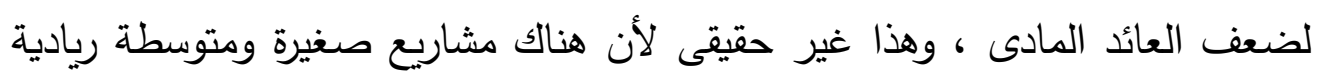

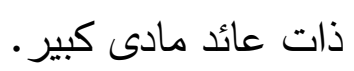

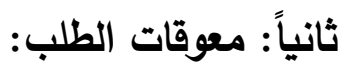

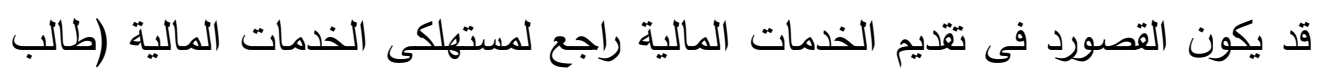

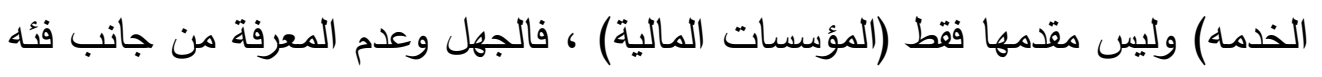

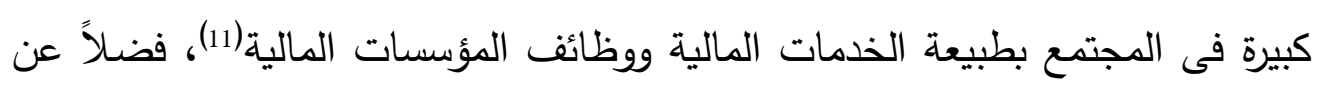

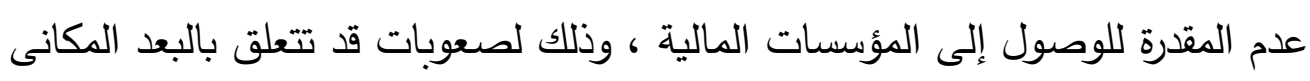

$\left.{ }^{11}\right)$ OECD/INFE, Financial Literacy and Inclusion: Results of OECD/INFE Survey Across Countries and by Gender, Financial Literacy \& Education Russia Trust Fund, Paris, 2013, p 36. 
وعدم وجود وسيلة مناسبة للوصول، وقد يلجأ بعض العملاء إلى طلب الخدمات الرسمية من القنوات غير الرسمية لاعتقادهم بوجود العديد من الفوائد سواء من حيث التكاليف أو الثقه او الراحه .

وقد يكون من ضمن المعوقات من جانب الطلب - المستهلك - هناك فئة من السكان غير نشطين اقتصادياً ، وليس لديهم الرغبة فى الدخول لدورة الإنتاج، وحتى لهن من لديه نشاط اقتصادى يتعامل بشكل كامل بالاقتصاد النقدى ، أى انهم يستخدمون النقد والأصول المالية كالذهب أو الأسهم أو تقديم القروض النقدية، أو أخذها بشكل غير رسمى من مقرضى الأموال لتلبية احتياجاتهم المالية ، ولكن هذه الطريقة غير

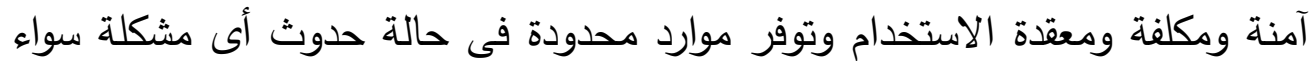
عجز أو مشكلة اقتصادية تتعلق بالمشروع، وطبقاً لتقارير ودراسات البنك الدولى فإن فوان الوصول إلى التمويل فى اللحظات الحرجة له أثر فى تحديد قدرة الأسرة على الخروج من الفقر أو عدم الرجوع إليه، وحيث ان النظام المصرفى الحالى يسعى إلى ان يكون

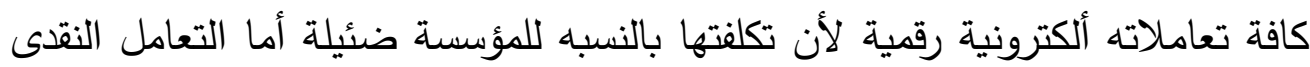
مكلف للبنوك من حيث تكلفة شركات المرافق المرتبطه باه من نقل وتخزين (12).

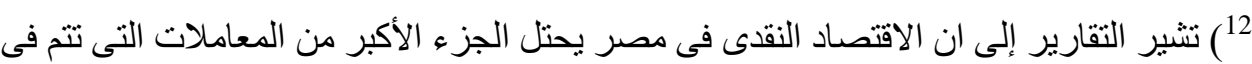

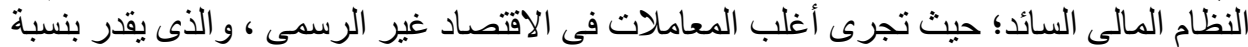

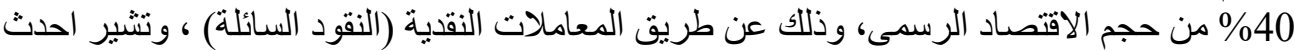

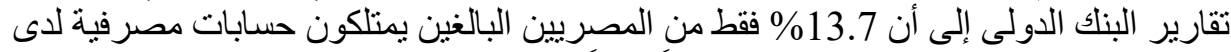

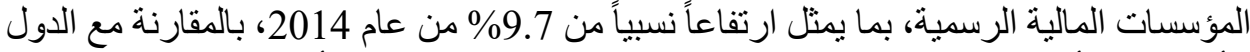

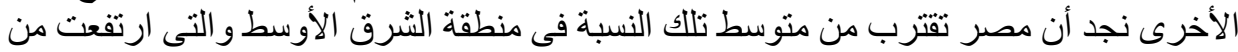

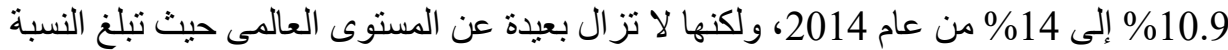

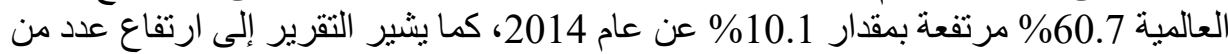

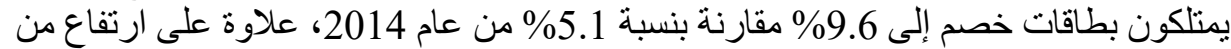
يدخرون لدى المؤسسات المالية الرسمية بنسبة 0.7\% \%

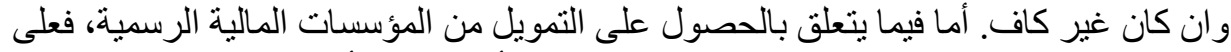

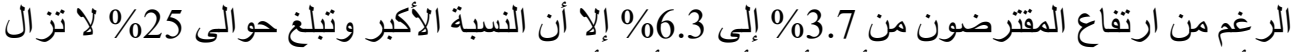

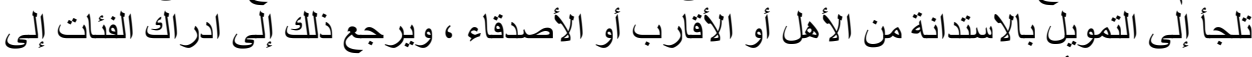

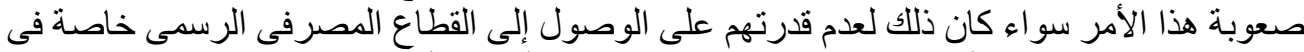

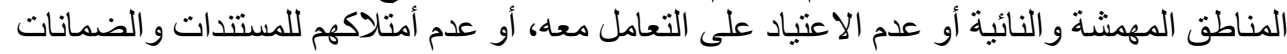




\section{الفصل الثانى \\ واقع الثمول المالى فى الدول العربية}

لا تزال الدول العربية ضمن أدنى المستويات فى العالم فيما يخص الثمول

المالى ، طبقاً لتقارير صندوق النقد الدولى فان من يمتلكون حسابات مصرفية مع مؤسسات مالية يمثلون 18\% من السكان ، وتتخفض هذه النسبة إلى 13\% عند النساء (13).

وبنظره متفحصه فى الواقع الداخلى للدول العربية فنجد أن هناك زيادة ملحوظة فى ملكية الحسابات للذكور والإناث بين عامى 2011 و 2014 فى معظم الدول العربية ماعدا دولتى الأردن والكويت. ففى عام 2014 كانت نسبة ملكية الحسابات

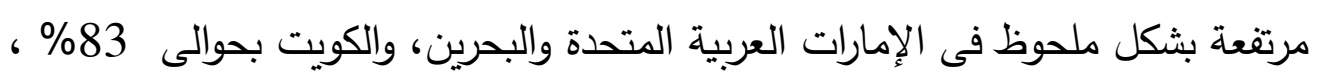

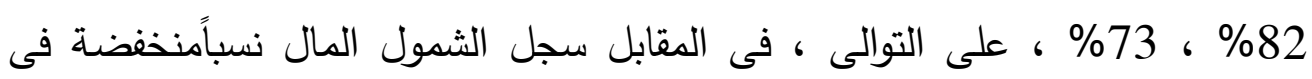

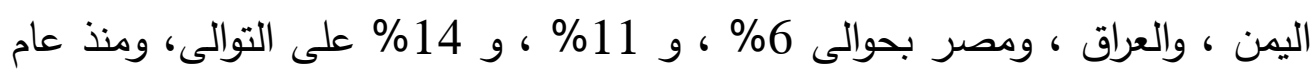

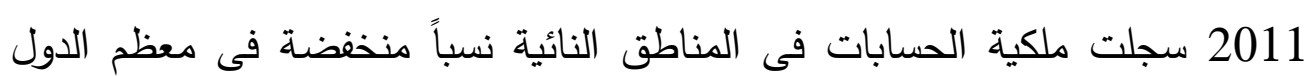
العربية : 8.7\% فى جيبوتى ، و 7.6\% فى العراق ، و 5.2\% فى مصر والسودان.

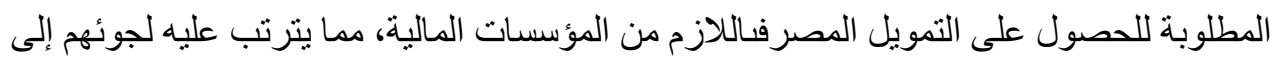

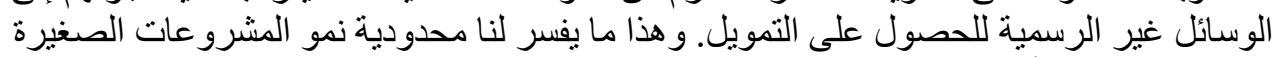

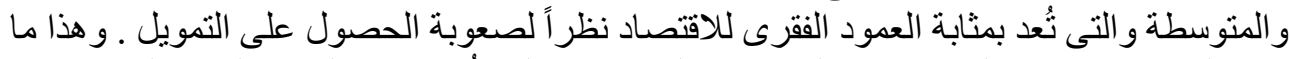

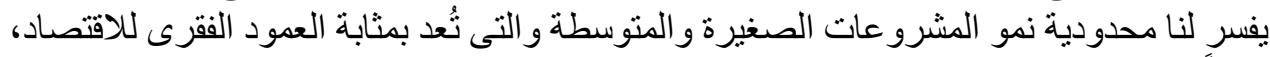

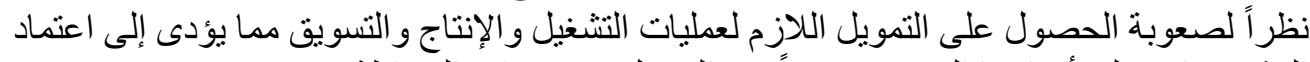

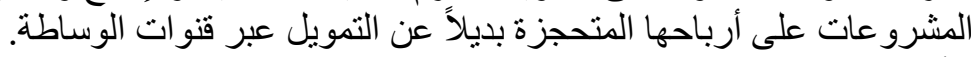

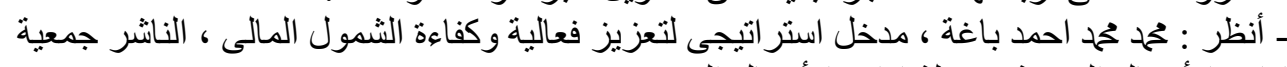

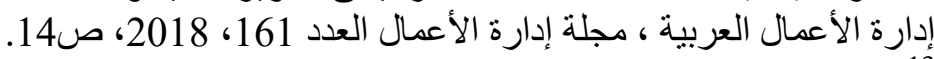

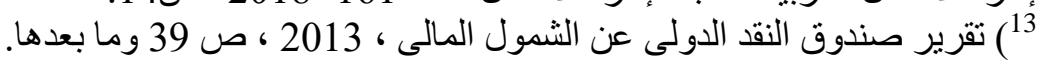


ويعود سبب إستمرار فجوة ملكية الحسابات بحسب الجنس إلى إمتلاك الذكور

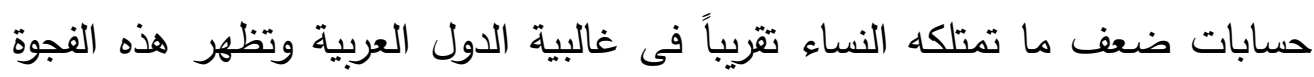
بشكل بارز فى اليمن والأردن، والسودان، والعراق، ومصر أنظر الجدول رقم (1).

الجدول 1: ملكية الحسابات في مؤسسات مالية كنسبة من البالفين فوق سن الـ15 عاماً

\begin{tabular}{|c|c|c|c|c|c|c|}
\hline \multicolumn{2}{|c|}{ stit } & \multicolumn{2}{|c|}{29} & \multicolumn{2}{|c|}{ المجموع } & \\
\hline 2014 & 2011 & 2014 & 2011 & 2014 & 2011 & \\
\hline 40.1 & 20.4 & 60.9 & 46.1 & 50.5 & 33.3 & الجزائر \\
\hline 66.7 & 48.8 & 90.2 & 79.0 & 81.9 & 64.5 & البحرين \\
\hline 的- & 8.8 & 的 & 16.6 & $+\hat{\varepsilon}$ & 12.3 & جيبوتئي \\
\hline 9.2 & 6.5 & 18.0 & 12.8 & 13.7 & 9.7 & مصر \\
\hline 7.4 & 7.5 & 14.6 & 13.5 & 11.0 & 10.6 & العراق \\
\hline 15.5 & 17.4 & 33.3 & 33.7 & 24.6 & 25.5 & الأرين \\
\hline 64.0 & 79.6 & 79.3 & 92.7 & 72.9 & 86.8 & الكويت \\
\hline 32.9 & 25.9 & 62.4 & 49.4 & 46.9 & 37.0 & لبنان \\
\hline 18.8 & 12.1 & 22.2 & 23.3 & 20.4 & 17.5 & عوريتانيا \\
\hline 郎 & 26.7 & $\cdot \cdot \hat{\varepsilon}$ & 52.0 & $+\varepsilon$ & 39.1 & المغنب \\
\hline$\cdot \hat{\varepsilon}$ & 63.5 & $+\varepsilon$ & 83.7 & $+\dot{\varepsilon}$ & 73.6 & كمان \\
\hline$\cdot \hat{-\varepsilon}$ & 61.6 & $\cdot+\cdot \hat{\varepsilon}$ & 68.6 & $+\dot{\varepsilon}$ & 65.9 & نُطر \\
\hline 61.1 & 15.2 & 75.3 & 72.7 & 69.4 & 46.4 & السعودية \\
\hline 6.0 & $-p \cdot \dot{\varepsilon}$ & 9.6 & $\cdot-\dot{\varepsilon}$ & 7.9 & $\hat{\theta} \cdot \dot{\varepsilon}$ & الصومال \\
\hline 10.0 & 4.4 & 20.2 & 9.4 & 15.3 & 6.9 & السودان \\
\hline$+\dot{\varepsilon}$ & 19.6 & - $\cdot \dot{\varepsilon}$ & 26.8 & $+\hat{\varepsilon}$ & 23.3 & سوريا \\
\hline 20.5 & $\cdot \cdot \hat{\varepsilon}$ & 34.1 & - م-غे & 27.3 & $\cdot \cdot \dot{\varepsilon}$ & تونس \\
\hline 66.3 & 47.2 & 89.8 & 68.8 & 83.2 & 59.7 & الإمارات العريبة المتحدة \\
\hline 21.2 & 10.2 & 27.3 & 28.7 & 24.2 & 19.4 & نلسطبن \\
\hline 1.7 & 1.1 & 11.4 & 6.4 & 6.4 & 3.7 & اليمن \\
\hline
\end{tabular}

ومما هو جدير بالذكر أن العلاقة بين الإقصاء المالى ومستوى الدخل لا تزال واضحه

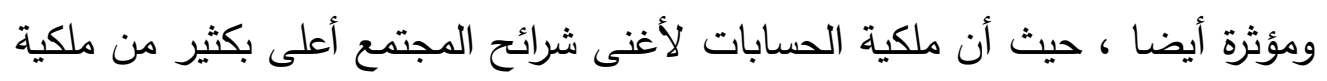
الحسابات لأفقر شرائح المجتمع فى جميع البلدان العربية.

ويظهر جدول (2) نسبة المقترضين من المؤسسات المالية الرسمية ، ومن قراءة

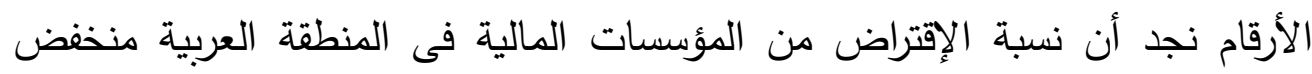

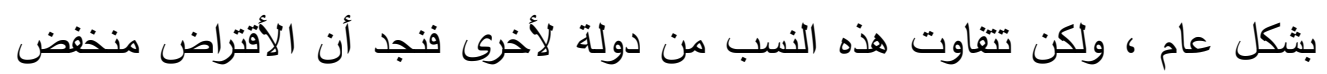


جداً فى الدول الأقل نمواً مثل اليمن والصومال، فيما هو مرتفع فى البحرين ولبنات والإمارات العربية المتحدة. والجدير بالذكر أن فى جميع الدول العربية باستثاء الجزائر واليمن ، تزيد نسبة المقترضين الذكور على نسبة المقترضين الإناث ، مما يفسر بأن بأن النساء تعانى من الغقصاء المالى أكثر من الرجال وبالتالى تفتقر إلى الأدوات المالية

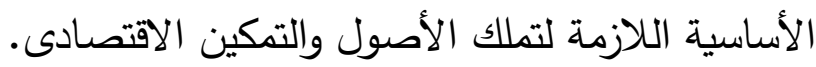

الجدول 2: نسبة البالفين الذين اقترضوا من المصارف التجارية أو من المؤسسات المالية في العام 2014

\begin{tabular}{|c|c|c|c|c|c|}
\hline أغنى 60 \% & أهقر 40 \% & إناث & נكور & مجموع & \\
\hline 3.0 & 1.1 & 3.0 & 1.3 & 2.2 & الجزائر \\
\hline 22.1 & 20.2 & 15.5 & 24.6 & 21.3 & البحرين \\
\hline 5.9 & 2.3 & 3.8 & 5.3 & 4.5 & جيبوتي" \\
\hline 6.6 & 5.8 & 4.9 & 7.6 & 6.3 & مصر \\
\hline 5.1 & 2.6 & 2.3 & 6.1 & 4.2 & العراق \\
\hline 15.4 & 10.8 & 10.3 & 16.7 & 13.6 & الأردن \\
\hline 14.9 & 12.8 & 13.5 & 14.5 & 14.1 & الكويت \\
\hline 17.5 & 12.5 & 10.9 & 20.8 & 15.6 & لبنان \\
\hline 9.4 & 5.1 & 7.1 & 8.3 & 7.7 & موريتانيا \\
\hline 5.1 & 3.2 & 3.6 & 5.0 & 4.3 & المغرب" \\
\hline 8.8 & 9.8 & 6.2 & 12.2 & 9.2 & عمان" \\
\hline 16.1 & 8.7 & 9.8 & 14.2 & 12.6 & قطر" \\
\hline 14.5 & 9.0 & 5.7 & 16.8 & 12.2 & السعودية \\
\hline 2.0 & 2.1 & 1.4 & 2.7 & 2.0 & الصومال \\
\hline 4.8 & 3.3 & 3.4 & 5.0 & 4.2 & السودان \\
\hline 13.7 & 12.4 & 11.5 & 14.7 & 13.1 & سورياء \\
\hline 10.1 & 4.9 & 6.2 & 9.9 & 8.0 & تونس \\
\hline 16.7 & 13.6 & 8.6 & 18.1 & 15.4 & الإمارات العربية المتحدة \\
\hline 5.3 & 2.6 & 2.8 & 5.7 & 4.2 & فلسطين \\
\hline 0.6 & 0.2 & 0.4 & 0.4 & 0.4 & اليمن - اليم \\
\hline
\end{tabular}

المصدر: البنك الدولي، المؤشر العالمي لتعميم الخدمات المالية 2014. :ـ أرقام 2011.

ويظهر جدول (3) نسبة الغقراض الرسمى والإقراض غير الرسمى ، وعند قراءة

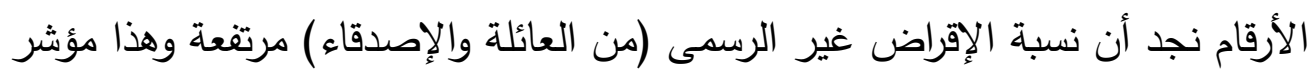
على أن هناك قصور فى المؤسسات المالية والنقدية الرسمية ، وانها لا تقوم بدورها

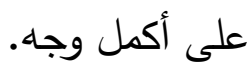


جدول 3: الإقتراض بحسب مصدر التمويل، 2014

\begin{tabular}{|c|c|c|c|}
\hline 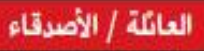 & الالإراض غير الرسمي الخاص & المؤسسات المالية & \\
\hline 13.2 & 1.5 & 2.2 & الجرائر \\
\hline 36.4 & 13.3 & 21.3 & البحرين \\
\hline 18.3 & 4.8 & 4.5 & جيبوتّي" \\
\hline 21.5 & 2.5 & 6.3 & مصر \\
\hline 48.2 & 19.8 & 4.2 & العرأ \\
\hline 17.4 & 1.1 & 13.6 & الأردن \\
\hline 30.2 & 12.0 & 14.1 & الكويت \\
\hline 12.9 & 4.4 & 15.6 & لبنان \\
\hline 29.8 & 5.1 & 7.7 & موريتانيا \\
\hline 40.9 & 1.9 & 4.3 & المغنب" \\
\hline 33.1 & 6.6 & 9.2 & "sles \\
\hline 30.6 & 8.9 & 12.6 & تُطر" \\
\hline 37.3 & 18.3 & 12.2 & السعودية \\
\hline 40.7 & 9.3 & 2.0 & الصومال \\
\hline 38.0 & 1.6 & 4.2 & السودان \\
\hline 20.1 & 16.9 & 13.1 & سوريا" \\
\hline 16.1 & 3.3 & 8.0 & تونسن \\
\hline 28.5 & 5.9 & 15.4 & الإمارات العربية المتحدة \\
\hline 25.7 & 8.5 & 4.2 & تلنسطبن \\
\hline 51.7 & 15.0 & 0.4 & اليمن - الين \\
\hline
\end{tabular}

\section{المبحث الأول}

الثمول المالى وتمويل المشروعات الصغيرة والمتوسطة 
يعتبر تحقيق التتمية المستدامة من أهم استراتيجيات الثمول المالى وذلك من خلال تنفيذ إستراتيجيات الثمول المالى ، هو تتمية مستدامة لقطاع التمويل والحصول على خدمات مالية رسمية، بما فى ذلك التمويل المتاهى الصغر وتمويل المشروعات الجديدة يمكن أن تساعد القطاعات محدودة الدخل وخاصة فى المناطق النائية وتتفاوت نسب التمويل فى كل دولة مقارنة بالناتج القومى لها كما هو موضح بالرسم البيانى رقم

\section{(بسم بياني 1: الأتثان المحلي المقدم من القطاع المالي (كنسبة مئوية من الناتج المحلي الإجمالي)}

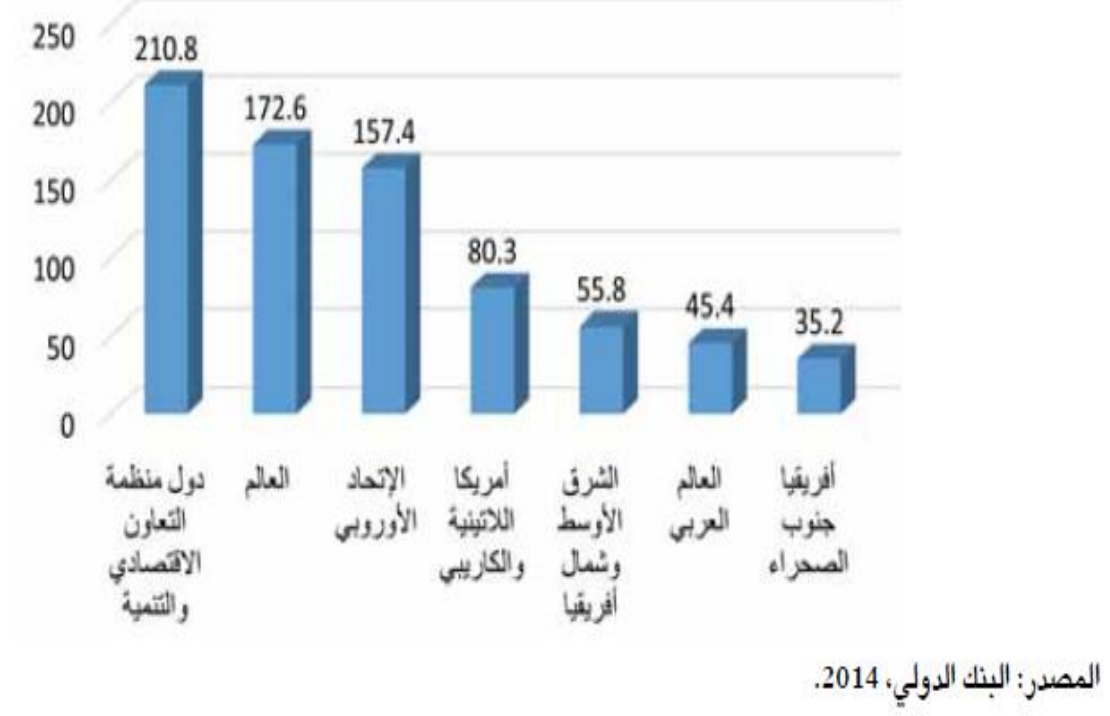

يُعد الحصول على التمويل من أكبر التحديات التى تواجه المشروعات الصغيرة والمتوسطة والمتناهية الصغر فى المنطقة، حيث إن 63\% من تلك المشروعات لا تحصل على التمويل وبحسب مؤسسة التمويل الدولية (IFC) ، تبلغ فجوة التمويل للمشروعات الصغيرة والمتوسطة فى المنطقة العربية بين 160 -180 مليار دولار ، بالإضافة إلى ذلك أظهرت دراسة مشتركة بين اتحاد المصارف العربية والبنك الدولى دئى أن 8\% فقط من التمويل المقدم من القطاع المصرفى العربى فى العام 2011 ذهب 
للمشروعات الصغيرة والمتوسطة وتتفاوت النسب بين الدول العربية حيث بلغت نسبة التمويل فى الجزائر 24\% من مجمل محفظة التمويل المصرفى عام 2011، و 20\% فى اليمن ، 16\% فى لبنان ، مقابل 5\% فى مصر ، و 2\% مو مى دول الخليج.

\section{رسم بياني 2: نسبة البالفين الذين اقترضوا المال لبذء أوتشفيل أوتوسيع عمل تجاري، 2014}

13.9

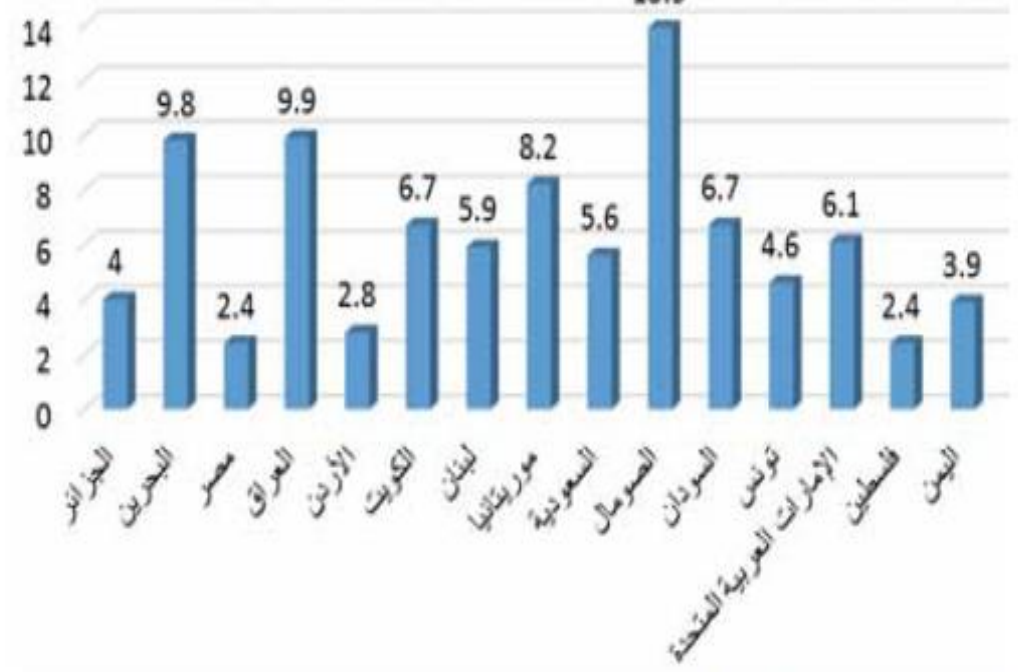

المصدر: البنل الدولي، المؤشر العالمي لتعميم الخدمات المالية 2014.

المبحث الثانحى

دور البنية التحتية المالية فى تعزيز الشمول المالى العربى

انتشار خدمات البنية التحتية المالية

هناك مجموعة من المؤشرات المهمة لقياس الثمول المالى ، والتعرف على مدى

انتشار خدمات البنية التحتية للقطاع المالى والمصرفى، فعلى سبيل المثال انتشار الفروع المصرفية وأجهزة الصراف الآلى ، وانظمة الدفع والتسوية ، ونقاط البيع، 
والعمليات المصرفية الإكترونية ، ومدى استخدام التكنولوجيا مثل استخدام الهواتف المحموله فى إجراء عمليات التحويلات المالية.

تعتبر النظم الكفء للبنية التحتية للقطاع المصرفى ، من أهم العوامل التى تؤدى إلى تحسين كفاءة وصول التمويل والخدمات المالية والمصرفية إلى مختلف فئات التئي وقطاعات المجتمع ، ويجب بذل مزيد من الأهتمام لتطوير هذه النظم فى الاقتصاديات

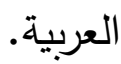

\section{انتشار الخدمات المالية الرقمية فى الاقتصاديات العربية:}

مما لا شك فيه أن ثورة التكنولوجيا التى يشهدها العصر الحديث لها تأثيرها على

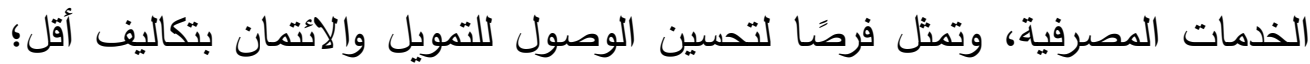

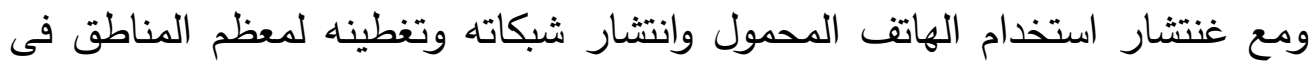

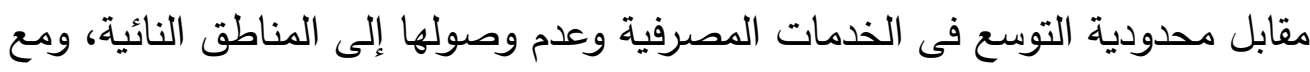
ذلك لا يزال انتشار خدمات الصيرفة عبر الهاتف الدحمول فى مراحلها الأولى فى التى

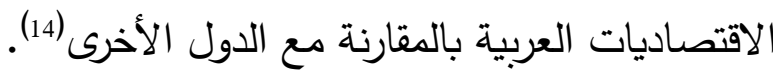

وقد تزايد حجم معاملات السداد غير النقدى فى مختلف دول العالم ، ووفقاً لتقرير الددوعات العالمية لعام 2016، فقد زاد حجم المعاملات غير النقدية على

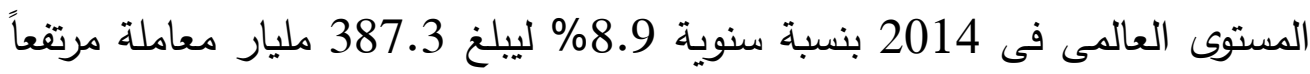
من 282.1 مليار معاملة فى عام 2010. وتتركز معظم هذه الزيادة فى منطقة شرق

14 محمح بسر برنية، نوسيع فرص الوصول للتمويل والخدمات المالية فى الول العربية ودور

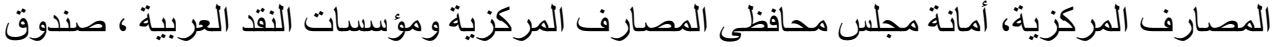
النقد العربى ، أبو ظبى ، 2012، ص صلئ 23 وما بعدها. 
آسيا (تحديداً الصين) بنسبة نمو بلغت 31.5\% ، أما عن معدل النمو فى الاقتصادات العربية فقد بلغ 12.3\%(15).

وتعتمد المجتمعات العربية على النقدية بثكل كبير ؛ حيثورد بتقرير البنك

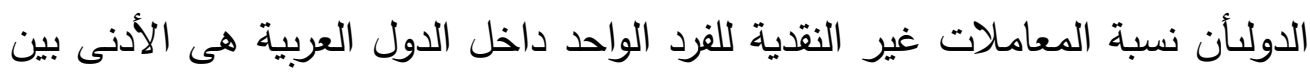

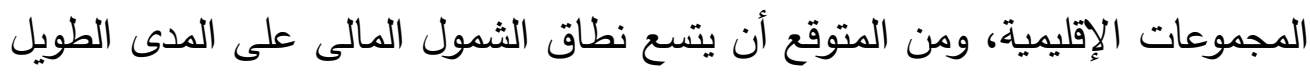

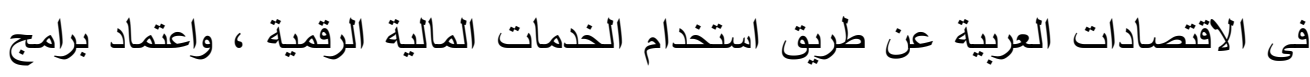
الدفع الخاصة بالحكومة الإلكترونية.

ويتحور دور البنوك المركزية كجهات إثرافية ورقابية فى تعزيز الثمول المالى،

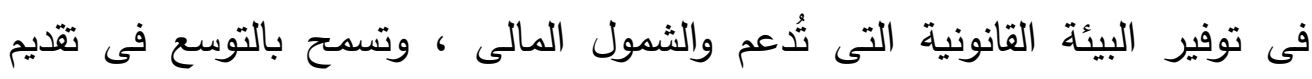
الخدمات المالية والمصرفية المختلفة بصور مبتكرة. وقد وفرت التكنولوجيا الرقمية

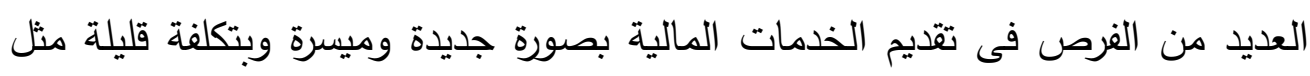
أجهزة الصراف الآلى والهواتف الدحمولة.

\section{الفصل الثالث \\ أثر الثمول المالى على التنمية المستدامة}

يقصد بالتمية المستدامة : التمية التى تلبى احتياجات الحاضر دون الإخلال

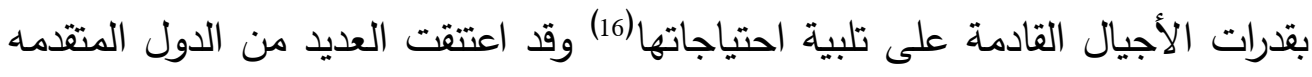

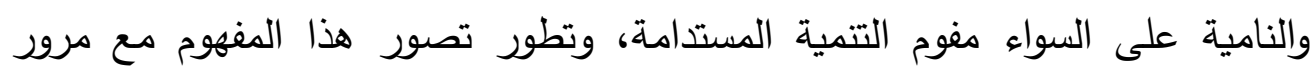

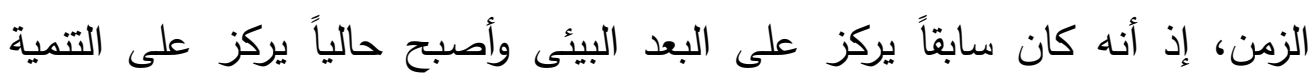
المستدامة بوصفها عملية تثتمل على أهداف اقتصادية واجتماعية وبيئية.

${ }^{15}$ )Capgemini and BNP Paribas, World Payments Report 2016, 2016, p. 6 16 نوز اد عبدالرحمن الهيتى، التتمية المستدامة فى المنطقة العربية: الحالة الر اهنة و التحديات

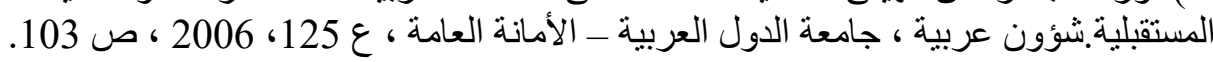


وقد ركزت التعاريف الحديثة بصورة أوضح على ثلاث ركائز للاستدامة وهى

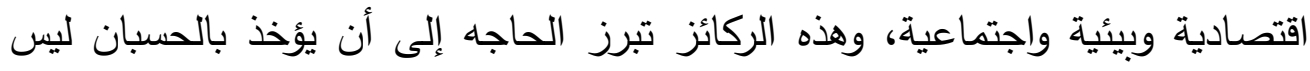

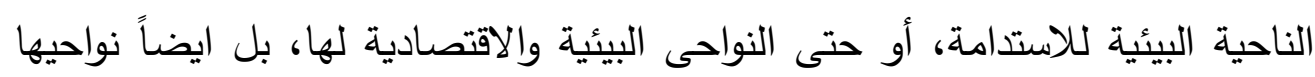
الاجتماعية(17).

تقوم التمية المستدامه على أساس الاستفادة من الموارد والامكانات المتاحة

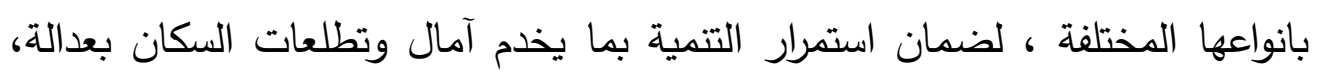
وبدون هدر للموارد على حساب الأجيال القادمه.

تسعى التتمية المستدامة إلى الكفاءة الاقتصادية، حيث تتطلب التكامل بين

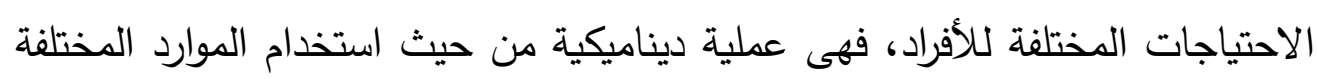

\section{المبحث الأول \\ مؤشرات التنمية المستدامة فى المنطقة العربية}

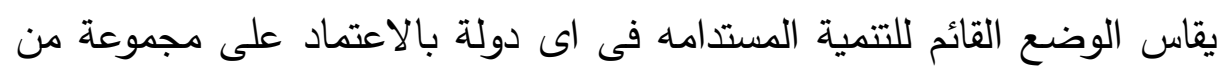

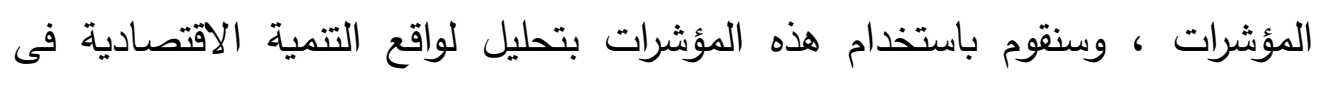

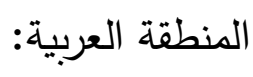

\section{أولاً : نصيب الفرد من الناتج المحلى:}

هذا المؤشر مع انه لا يقيس التتمية المستدامه قياساً كاملاً ، ولكنه يمثل عنصراً

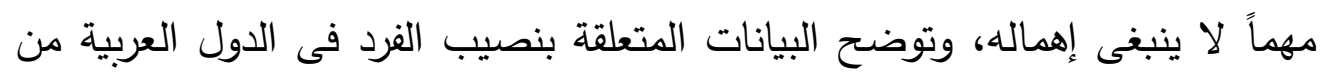

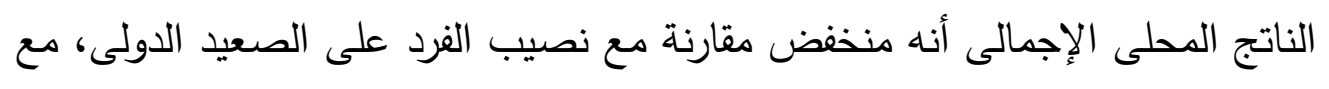
17 البنك الدولى ، تقرير عن التنمية فى العالم، التنمية المستدامه فى عالم دائم التغير ، و اثنطن ، .2003 


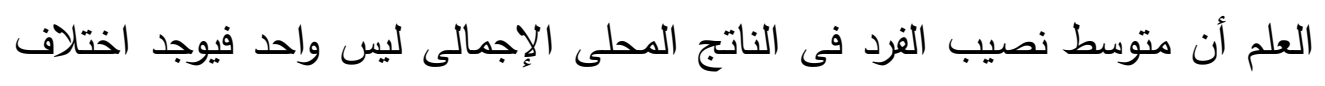

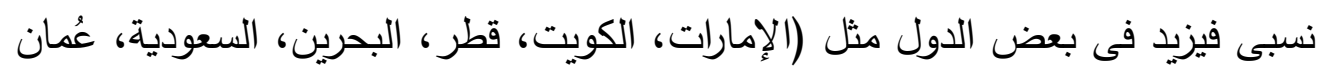

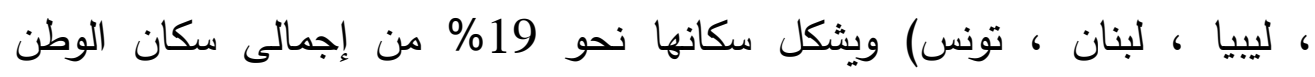

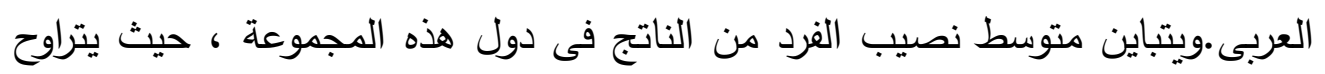

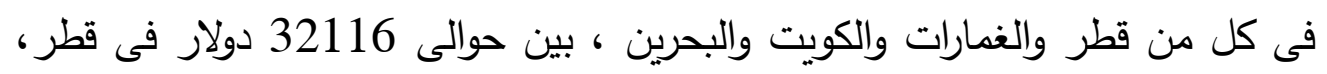

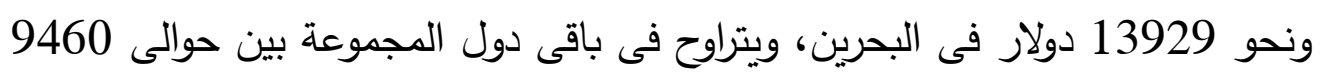
دولار فى السعوية وحوالى 2720 دولار فى تونس (18). ثانياً: نسبة إجمالى الاستثمار إلى الناتج المحلى الإجمالى: يقصد بهذا المؤشر نسبة الإنفاق على الأصول الإنتاجية فى الاقتصاد إلى الناتج الإنجا

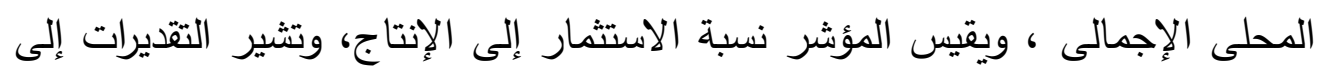

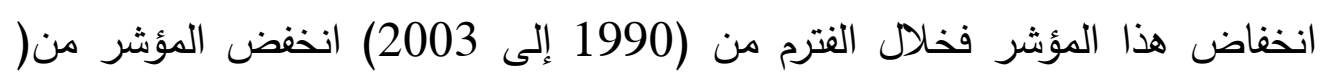

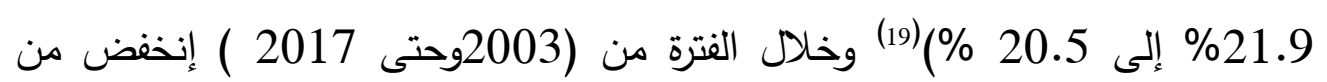
20.5\% إلى 20.1\%) (20) مع تفاوت هذه النسبة بين الدول العببية المختلفة.

ثالثاً: مجموع الدين الخارجى كنسبة مئوية من الناتج المحلى الإجمالى:

18 16 صندوق النقد العربى وآخرون: التقرير الاقتصادى العربى الموحد لعام 2014، أبوظبى ، 2014 ، 16 . 19 المرجع السابق. 20 المرجع السابق 
يقيس هذا المؤشر درجة مديونية الدول ويساعد فى تقييم قدرتها على تحمل الديون. ويربط المؤشر الدين بقاعدة الموارد، ما يوضح مدى قدرة البلد على نقل الموارد إلى إنتاج الصادرات بقصد تعزيز القدرة على السداد.

وتتفاوت الدول العربية المدينة فيما بينها فيما يتعلق بهذا المؤسر ما بين 178.2 فى موريتانيا كحد أقصى ، و 17.2\% كحد أدنى فى سلطنة عُمان(12).

ومما هو جدير بالذكر ، فإن نسبة الدين الخارجى إلى الناتج المحلى الإجمالى الذيا

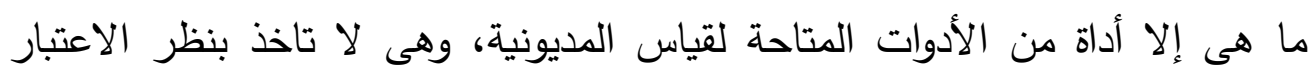

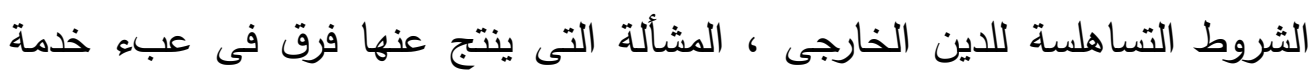

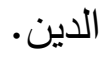

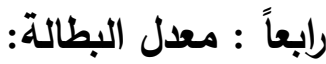

يشمل هذا المؤشر جميع أفراد القوى العاملة الذين ليسوا موظفين يتقاضون

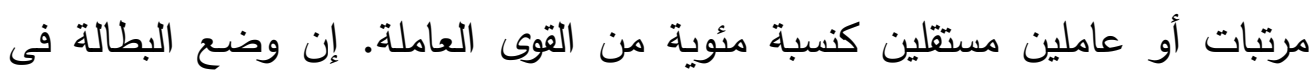

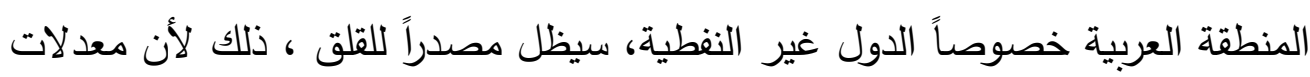

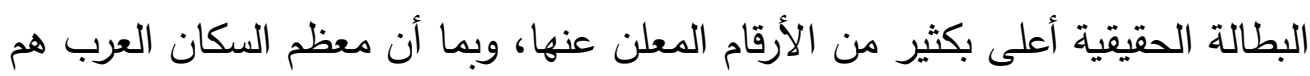

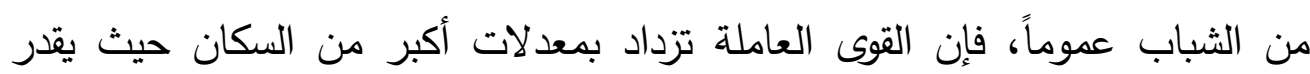
معدل نموها السنوى بنحو 3.4\% خلال الفترة 1995 - 2002. مقارنة بمعدل النمو السنوى للسكان البالغ حوالى 2.4\% خلال الفترة ذاتها. وقد نما معدل القوى العاملة

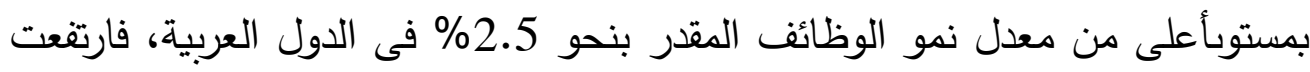

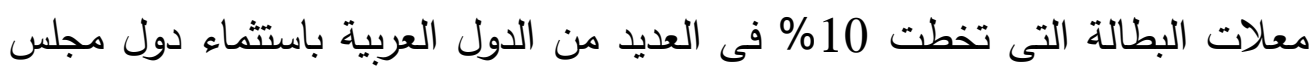

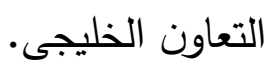

${ }^{21}$ ) Economist Intelligence Unit (EIU), Country Risk Service. http://www.eiu.com 
وانتشرت البطالة بدرجات متزايدة بين الداخلين الجدد لسوق العمل خاصة من

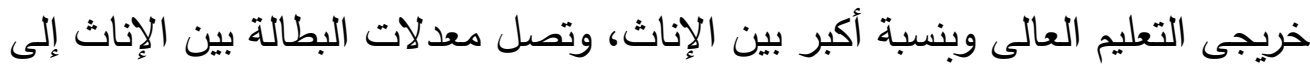

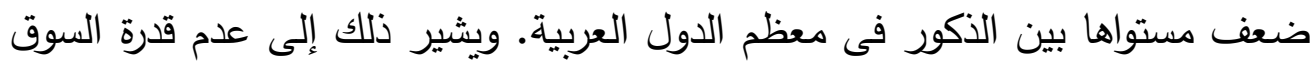

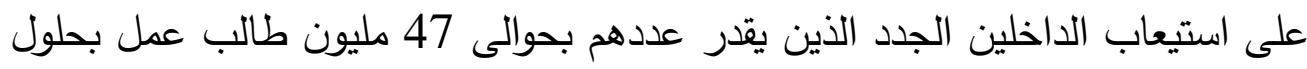

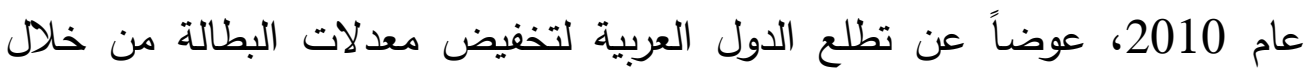
استيعاب العاطلين عن العمل الحاليين فى سوق العمل أيضاً (22).

\section{المبحث الثانى}

\section{الثمول المالى ركيزة اساسية لتحقيق أهداف التنمية المستدامة}

يمثل الثمول المالى ركيزة أساسية لتحقيق أهداف التتمية المستدامه وذلك على النحو

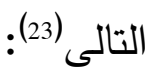

ه الثمول المالى والقضاء على الفقر : طبقاً لتقارير البنك الدولى ، هناك أكثر

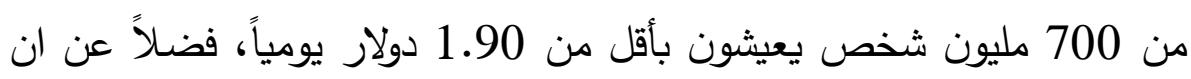
فرص حصولهم على الخدمات المالية تكاد تكون منعدمه، مما يجعل من الصعب عليهم تسيير حياتهم الاقتصادية ، وتثير قاعدة البيانات العالمية

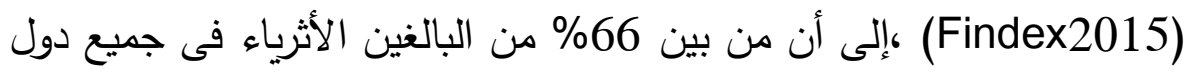

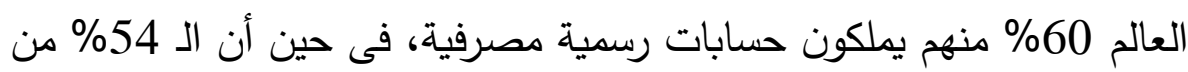
البالغين الفقراء، 40\% منهم ليس لهم حسابات مصرفية.هذه الفجوة تعكس جيداً عدم وصول الخدمات المالية التى من شأنها أن تخلق ما يسمى بدوامة لئه الفقر

22 23 صندوق النقا العربى وآخرون : التقرير الاقتصادى الموحد لعام 2004، مرجع سابق ، ص 34. 23

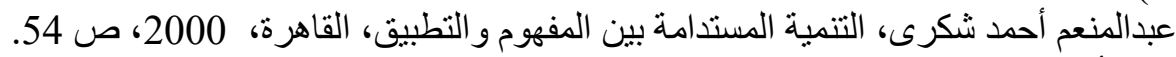

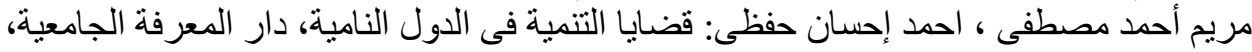

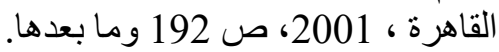


من ضمن الخدمات المالية التى قدمها نظام الثمول المالى هى خدمة الادخار، وعندما تتوفر هذه الخدمة للأفراد تساعدهم على زيادة مقدرتهم فى هي هئ مواجهة الأزمات المالية ، وتعمل على تتظيم استهلاكهم ، فضلاً عن قدرتهم على حيازة الأصول الإنتاجية. يساهم الثمول المالى فى الحد من الجوع وتعزيز المن الغذائى : وفقاً لتقارير منظمة الأغذية والزراعة للأمم المتحدة (2015 2AO)، هناك حوالى 795 مليون شخص يعانون من نقص الغذاء على الصعيد العالمى، وهؤلاء الأشخاص معظمه يعيش فى المناطق النائية البعيدة عن التغطية المصرفية، مما يقلل من فرص حصولهم على الخدمات المصرفية المختلفة مثل الائتمان والتأمين على محاصيلهح الزراعية، ويحد من قدرتهم فى زيادة استثماراتهم الزراعية. وبلا شك فالشمول المالى قد لعب دور جوهرى فى زيادة الإستثمار

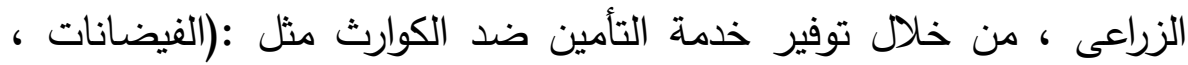
والسيول ، والجفاف)، ومكن هؤلاء الفراد من إدرخار أرباحهم ، مما يساعدهم فى المستقبل على تلبية إحتياجاتهم الرأسمالية من معدات زراعية وبذور ...ألخ، فضلاً عن ذلك فقد ساهمت الخدمات المالية الرقمية ، فى تسهيل عملية توزيع الأجور والإعانات على المزارعين. يساهم الثمول المالى بلا شك فى تحسين مستوى الصجة وذلك من خلال مجموعة الخدمات التى يقدمها فمثلاً: خدمة الادخار تساعد الأفراد على إدارة نفقاتهم الطبية سواء المخطط لها أو غير المخطط لها ، وخدمة التأمين تجعل الأفراد فى حالة استقرار وعدم قلقل او خوف من المستقبل وما تقوم به الحكومة المصرية الآن بناء على توجيهات رئيس الجمهورية من تعميم خمة التامين الصحى الثامل على كافة إنحاء الجمهورية لهو خير مثال لتطبيق الثمول المالى فى قطاع جوهرى وحساس يهم كافة أفراد المجتمع، وطبقاً لتقارير البنك الدولى ومنظمة الصحة العالمية فإن من اسباب بقاء الأشخاص فى دوامة 
الفقر فى الدول النامية ، هى المدفوعات النقدية المنفقة على الرعاية الصحية ، التى تستوعب كامل مدرخاتهم ودخولهم فى معظم الأحيان. الثمول المالى له مردود ليس ضئيل على العملية التعليمية ، حيث اثبتت الإحصائيات أن هناك حوالى 57 مليون طفل فى سن التعليم الأساسى غير ملتحقين بالعملية التعليمية ، وهناك ارتباط وثيق بين جودة العملية التعليمية من جانب وقدرة الأسر على الإستثمار فى فرص التعليم من جانب أخر (العلاقة

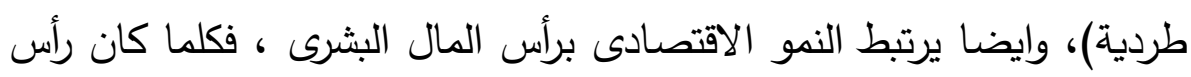
المال البشرى مدرب بشكل كفه كلما ساعد ذلك على ارتفاع مستويات التتمية ، وعلى النقيض فإن ضعف الأداء التربوى من شأنه أن يحد من التنمية. والمردود الايجابى للشمل المالى على العملية التعليمية يتمثل فى أن خدمة الإدخار تساعد الأفراد على إدارة نفقات التعليم، واكدت بعض الراسات بأن هناك زيادة بنسبة 20\% فى الإنفقاق على التعليم للأسر التى تمكنت من فتح حسابات مصرفية ، وان خدمة القروض الصغيرة ذات الأجال القصيرة ، قد الد ساعدت السر على دفع نفقات التعليم. يساعد الثمول المالى على زيادة النمو الاقتصادى، فالحرمان المالى لطائفه من الأفراد داخل المجتمع له آثاره السلبية على النمو الاقتصادى، فلا تزال هناك فجوة كبيره بين الفقراء والأغنياء فى الحصول على التعليم والصحة فى الى الدول النامية، ويتيح الثمول المالى لهذه الفئات الوصول للخدمات والمنتجات المالية مثل : تعبئة المدخرات وتوجيهها نحو تمويل المشروعات الامنتجة، ومع التطور التكنولوجى والتقنيات الحديثه ساعد استخدام هذه التكنولوجيا مثل الهاتف المحمول فى تحسين وصول الخدمات المالية للمناطق النائية التى لا تتوافر بها فروع رسمية للمؤسسات المالية مما يمكن الأفراد من الإستفاده من الخدمات المالية.

أهمية تكوين رأس المال لتحقيق التنمية الاقتصادية: 
تستهدف عملية التنمية الاقتصادية الارتفاع السريع بمعدل نمو الناتج القومى،

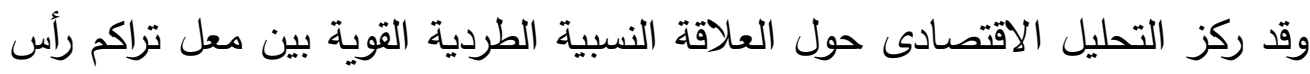

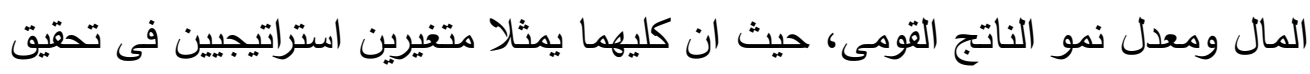

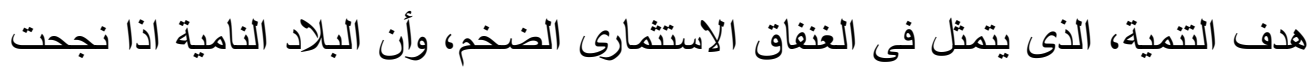

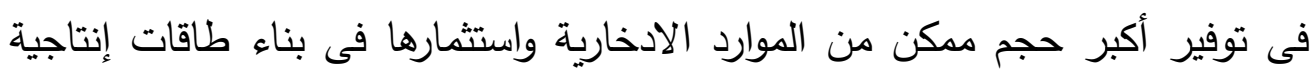

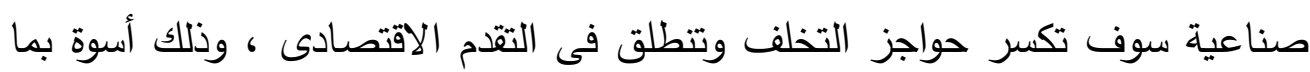

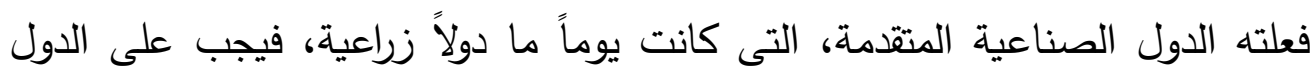

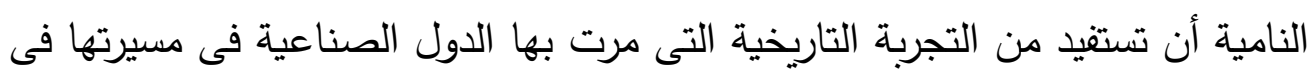

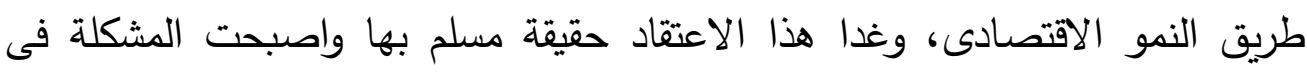

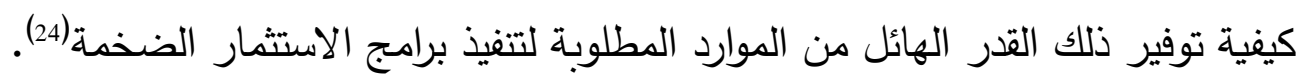

وقد اكد " روسو" فى نظريته عن مراحل النمو إلى أنه لكى تصل الدول النامية

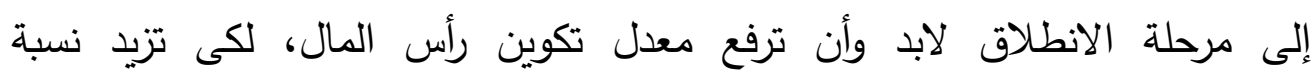
الاستثمارات المنتجة إلى 10\% من ناتجها القومى.

وكذلك أكد " آرثر لويس" أن نجاح عملية التتمية تتوقف على تحقيق زيادة كبيرة

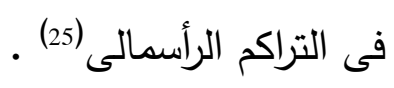

ومما هو لا شك فيه أن عملية الثمول المالى تهدف إلى زيادة مقدرة الاقتصاد

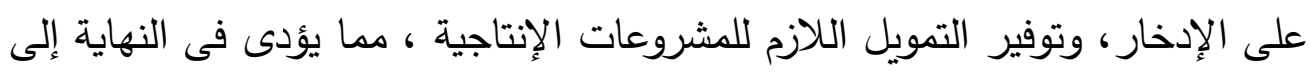
زيادة التكوين الرأسمالى ، وتحقيق التتمية الاقتصادية.

\section{المبحث الثالث}

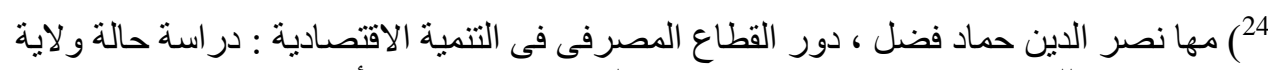

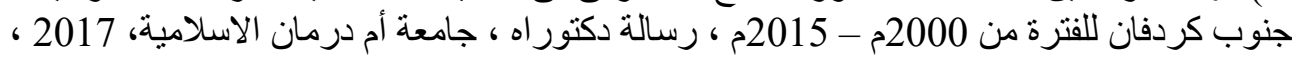




\section{متطلبات تعزيز الثمول المالى فى الدول العربية}

مما هو لا شك فيه أن توسيع نطاق الثمول المالى فى الدول العربية، لهو متطلب من متطلبات التنمية الاقتصادية ، ففى ضوء الحاجة الكبيرة لتطوير إستراتيجيات لتحقيق النمو الاقتصادى الأكثر شمولية الذى يساعد على مواجهة

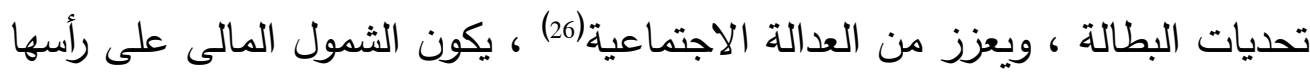

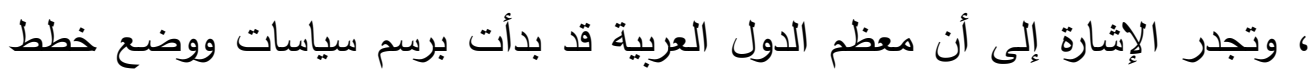
وبرامج لتحقيق أهم المتطلبات التى يجب التركيز عليها والمتمثله فى :

يجب على الحكومات وضع أطر تتظيمية ومؤسسية سليمة، مع توفير المعلومات، واعتماد تدابير مباشرة، كتقديم الإعانات وفرض شروط إلزامية تضمن تحقيق الشمول المالى (27). العمل على تطوير القوانين والنظمة والطر الرقابية التى تساعد على تحسين إنتثار الخدمات المالية والمصرفية(28). الاهتمام بالتثقيف المالى ونشره بين كافة طوائف المجتمع، مع وضع برامج لتدريب الأفراد على استخدام الخدمات المالية من خلال القنوات والمؤسسات

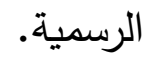

دراسة معوقات الثمول المالى ومن أهمها الفجوة بين العرض والطلب الخدمات المالية - مع وضع استراتيجية وطنية لإزالة تلك المعوقات. المشاركة الجادة بين القطاع الحكومى والقطاع الخاص لتوفير بنية مالية تحتية قوية ، مع غتاحة الخدمات والمنتجات المالية(29).

26) إتحاد هيئات الاوراق المالية العربية، الخطة الاستر اتيجية لاتحاد هيئات الأور اق المالية العربية

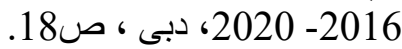

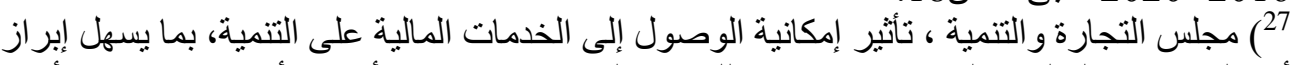

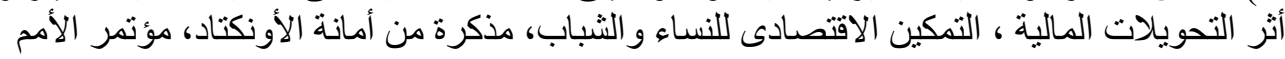

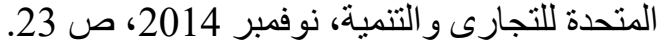


العمل على توسيع نطاق شبكة الانترنت وتوفيرها فى المناطق النائية ، وذلك يعمل على تسهيل عملية وصول الخدمات المالية والمصرفية الرسمية للفئات المحرومه من الخدمات المالية ، مما يمكنه من الإدخار ، والحصول على

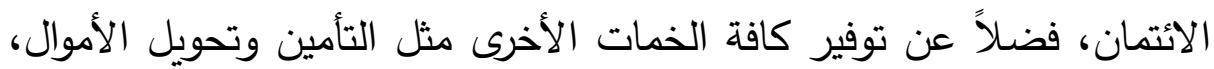
مما ينعكس ايجابياً على أوضاعهم الاجتماعية والاقتصادية(30). النظر فى احتياجات كافة فئات المجتمع، والعمل على ابتكار منتجات مالية تتناسب مع هذه الاحتياجات مع تطوير للخدمات المالية من خلال تصميم خدمات ترتكز على إحتياجات المجتمع ومتطلباته. تعزيز التنافسية بين مقدمى الخدمات المالية والمصرفية، بما يمكن المستهدفين من الإختيار ما بين المنتجات بسهولة وتكاليف معقولة وبشفافية. لا يمكن إنكار دور المشروعات الصغيرة فى دفع عملية التتمية الاقتصادية ، فيجب إحتواء تلك المشروعات ضمن النظام المالى الرسمى، مع توفير كافة الخدمات المالية ، وبالأخص الائتمان ، مما ينعكس على زيادة حجم المدخرات الوطنية ، وتفير الائتمان الضرورى للتتمية الاقتصادية. ضرورة التعاون بين المؤسسات المالية الدولية ، حيث أن معظم الدول العربية لم تصل لارجة عالية فى الارتقاء بالشمول المالى وتطبيقه كما ينبغى، فلابد من

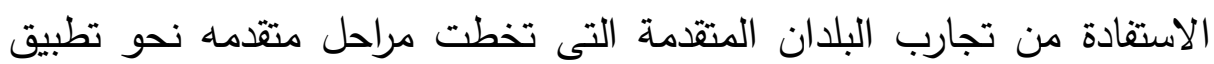
الشمول المالى. هناك الكثير من الأفراد او المؤسسات قد يمتنعون عن التعامل مع القنوات المالية الرسمية لأسباب أيدلوجية او دينية فيجب العمل العل على هذه النقطة ،

\footnotetext{
29) موسى عبدالعزيز شحاته، وآخرون : التوجه الإستر اتيجى للإستقرار المالى و الإجتماعى، مجلة

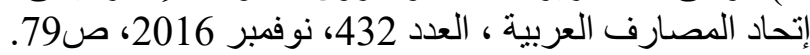

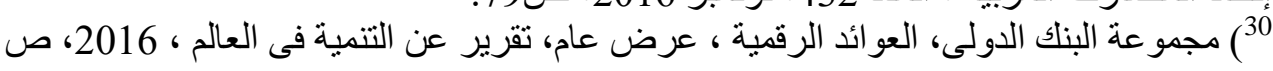


وتوفير الخدمات المالية الإسلامية ضمن نشاط المؤسسات المالية الرسمية وذلك لجذب كافة طوائف المجتمع العربى على إختلاف إنتماءاته وتوجهاته.

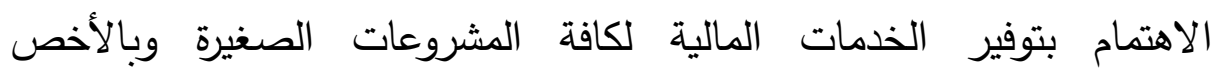
المشروعات المنزلية ولفئة النساء ، بما يشجعهم على تطوير مشاريعهن ، وزيادة الإنتاجية ، والمشاركة فى التتمية الاقتصادية(31).

${ }^{31}$ ) K. Mlambo Financial Inclusion and Regulation: Trade OFFS and Synergies in developing countries. P 15. 


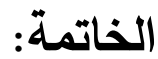

يُعد الثمول المالى ركيزة اساسية من ركائز تحقيق التتمية المستدامة، فإنتشار

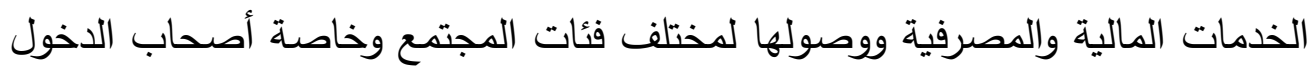
المتننية ومحدودى الدخل، فسيساهم ذلك فى مكافحة الفقر والجوع، والحد من البطالة الكئل بتوفير فرص العمل ، وتمويل المشروعات الصغيرة والدتوسطة ، وتعزيز العدالة

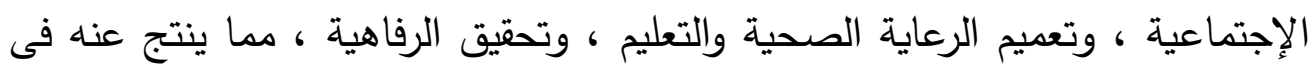
النهاية تحقيق التتمية المستدامة.

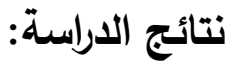

من خلال الدراسة تم الوصول لمجموعة من النتائج تتمثل فى :

من قراءة الأرقام نجد أن هناك تفاوت واضح بين الدول العربية فيما يخص تعميم

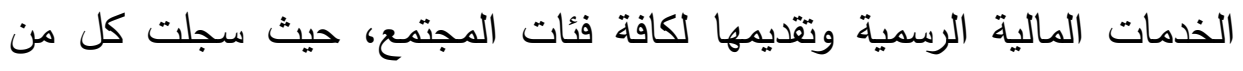

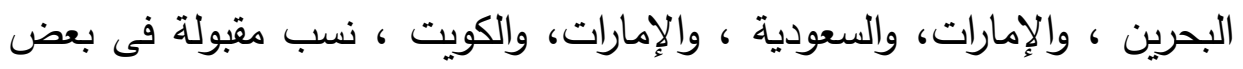

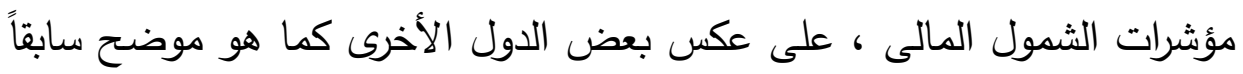

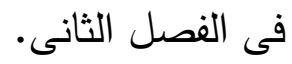
ت تتسم كافة الدول العربية بضعف مستوى التمويل الرسمى، وعدم التكافؤ بين

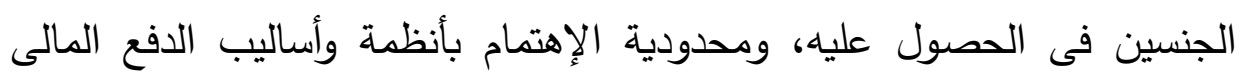

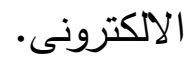

من شأن الثمول المالى وتوسيع إنتشار الخذمات المالية ، المساهمة فى زيادة الثقة فى النظام المالى والمصرفى الرسمى ، وتعزيز شفافية المعاملات المالية. 


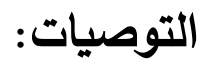

العمل على تطوير البنية التحتية للقطاع المصرفى والنقدى خاصة فى المناطق النائية، والعمل على ابتكار أنظمة جديدة للضمانات وتسهيلها ، وتطوير نظم الدفع والعمليات المصرفية الإككترونية.

نشر الوعى الأئتمانى وإنشاء مكاتب للاستعلام الائتمانى وتوزيعها على كافة المناطق. صياغة قواعد قانونية تسهل إجراءات المعاملات المصرفية تتواكب مع التقدم التكنولوجى وتتمتع بالوضوح والثفافية.

العمل على تشجيع المشروعات الصغيرة والمتوسطة وتوفير كافة الخدمات المالية لها بصورة واضحه وبسيطة وميسرة.

تيسير الوصول للخدمات المالية بتكلفة أقل وأكثر فاعلية عن طريق تقديم الخدمات المالية الرقمية ، والدفع الإكترونى.

دمج قنوات التمويل غير الرسمية داخل مظلة النظام المصرفى وإخضاعهل لرقابة البنوك المركزيـة.

التوسع فى الإنتشار الجغرافى للمؤسسات المالية والنقدية وبالأخص فى المناطق النائية ، وذلك من خلال التوسع فى شبكة فروع المصارف ومقدى الخدمات المالية وخاصة التمويل المتناهى الصغر ، وإبتكار نقاط وصول للخدمات المصرفية وتطويرها مثل وكلاء المصارف، الصرآف الآلى ، والهاتف البنكى. 
تطويروتتويع الخدمات النقدية والمالية ، والعمل على تقديم خدمات جديدة ومبتكرة ، وذات تكلفة منخفضة.

توفير الحماية المالية للمستهلك عن طريق توعيته بكافة حقوقه وواجباته ، وايضا المزايا والمخاطر المتعلقة بالمنتجات المالية.

توسيع نطاق العمليات المالية والنقدية الإسلامية حيث ستكون دفعه قوية للشمول المالى ، حيث ان هناك الكثير من الأفراد والمؤسسات داخل نطاق الوطن العربى يفضلون العمليات المصرفية المتوافقه مع الشريعة الإسلامية. 


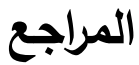

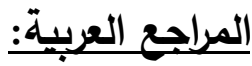

1. اثرف عمر عبدالقادر ، وأخرين : دور التقنية المحترفية فى نشر الثمول المالى : دراسة حالة ولاية الجزيرة،

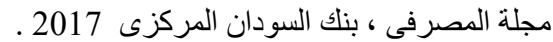
2. صبرى نوفل ، الثمول المالى فى مصر وبعض المرك الدول العربية، مقال ، مجلة الاقتصاد و المحاسبة ، ع 667، 2018

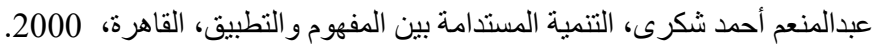

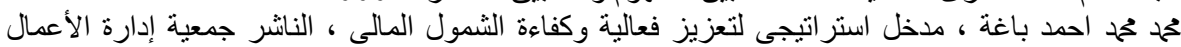

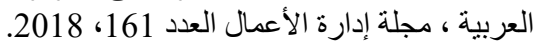

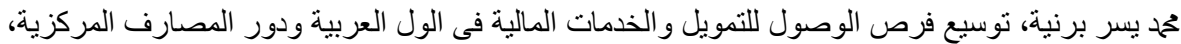

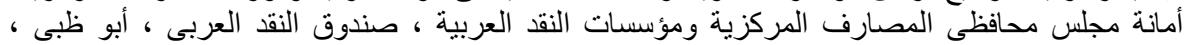
2012

مريم أحمد مصطفى ، احمد إحسان حفظى: قضايا التنمية فى الدول النامية، دار المعرفة الجامعية، القاهرة ، 2001

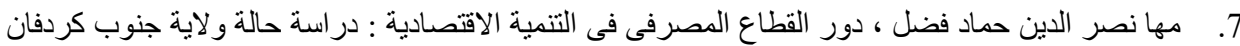

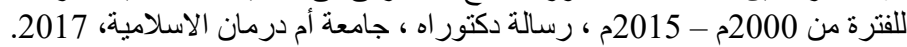

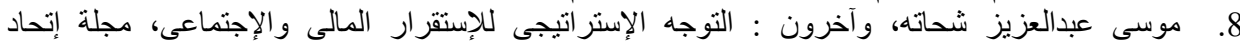

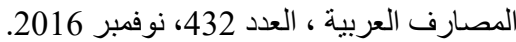
نورين مجدى المين ، الخدمات المالية بين الاستبعاد والثمول ، مجلة المدرف المصرفى، الناثر بنك السودان

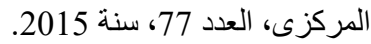

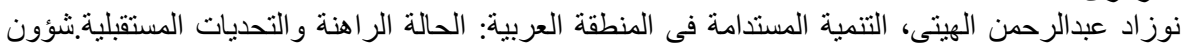

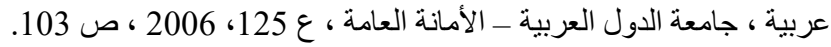

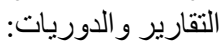

إتحاد هيئات الاوراق الماتية العاتية العربية، الخطة الاستراتيجية لاتحاد هيئات الأوراق المالية العربية 2016-

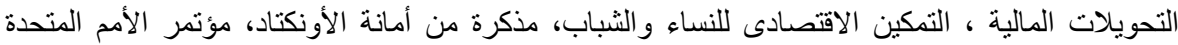

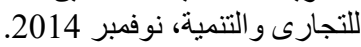

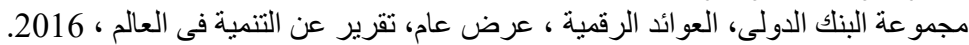

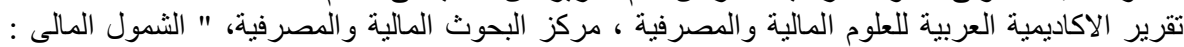

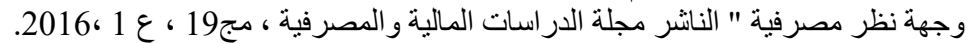

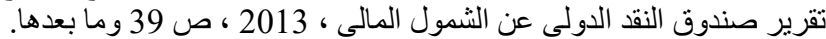

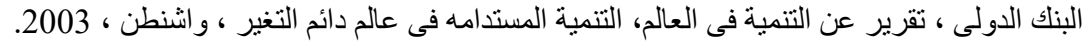

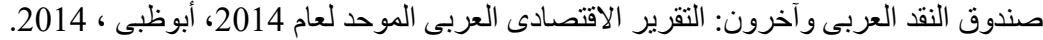

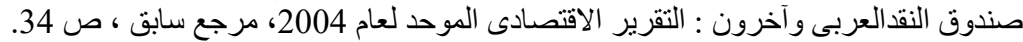

1. Adeyemi Adewale Abideen, Pramanik Ataul Huq, Meera Ahmaed Kameel Mydin, The measurement Model of the Determinants of financial Exclusion among Musilm Micrenterpreneurs in Ilorin, Nigeria, Journal of Islamic finance, Vol.1 No. 1 (2012), IIUM instititue of Islamic Banking and Finance, ISSN 2289-2117 (O)/2289-2109(P)

2. Douglas Randall and Jennifer Chien, "8 key approaches to accelerate financial inclusion", World Bank, 2017, See Web Site: http://blogs.worldbank.org. 
3. H R Khan: Financial inclusion and financial stability: are they two sides of the same coin Address by Shri H R Khan, Deputy Governor of the Reserve Bank of India, at BANCO , 2011, organized by the Indian.

4. http://ijsrm.in/special\%20issue\%202/3\%20ijsrm.Pdf

5. K. Mlambo Financial Inclusion and Regulation: Trade OFFS and Synergies in developing countries.

6. Njuguna N. Financial Innovation and Monetary Policy: Challenge and Opportunities for Monetary Reform, Kampala 0290.

7. Capgemini and BNP Paribas, World Payments Report 2016.

8. World Bank, 2015, The Little Data Book on Financial Inclusion. Institute of International Finance, 2015, Financial Inclusion: A Financial Industry Perspective

9. Bankers Association and Indian Overseas Bank, Chennai,4 November 2011.

10. OECD/INFE, Financial Literacy and Inclusion: Results of OECD/INFE Survey Across Countries and by Gender, Financial Literacy \& Education Russia Trust Fund, Paris, 2013, p 36.

11. Economist Intelligence Unit (EIU), Country Risk Service.

12. http://www.eiu.com 